Review Article

\title{
Crosstalk between Macrophages and Mesenchymal Stem Cells Regulated by Biomaterials and Its Role in Bone Regeneration
}

\author{
Fan Gong $\mathbb{D}^{1,2}$ Thomas Groth $\mathbb{D},{ }^{3,4}$ Chenlin Tu $\mathbb{D}^{1,2}$ Mingyan Zhao ${ }^{10},{ }^{1}$ Xinqia Huang $\mathbb{D}^{1},{ }^{1}$ \\ and Jiaqi Chu $\mathbb{D}^{1}$ \\ ${ }^{1}$ Stem Cell Research and Cellular Therapy Center, Affiliated Hospital of Guangdong Medical University, Renmin Dadao Road 57, \\ Xiashan District, Zhanjiang 524001, China \\ ${ }^{2}$ Department of Spinal Surgery, Affiliated Hospital of Guangdong Medical University, Zhanjiang 524001, China \\ ${ }^{3}$ Department Biomedical Materials, Institute of Pharmacy, Martin Luther University Halle-Wittenberg, \\ Heinrich-Damerow-Strasse 4, 06120 Halle (Saale), Germany \\ ${ }^{4}$ Laboratory of Biomedical Nanotechnologies, Institute of Bionic Technologies and Engineering, \\ I.M. Sechenov First Moscow State University, 119991 Trubetskaya Street 8, Moscow, Russia
}

Correspondence should be addressed to Mingyan Zhao; mingyan985927@163.com

Received 5 March 2021; Accepted 27 August 2021; Published 17 September 2021

Academic Editor: Lenka Zajičková

Copyright (c) 2021 Fan Gong et al. This is an open access article distributed under the Creative Commons Attribution License, which permits unrestricted use, distribution, and reproduction in any medium, provided the original work is properly cited.

\begin{abstract}
Impaired bone healing caused by severe trauma, infection, and tumor resection is an extremely common phenomenon. Therefore, the treatment of bone defects represents a major clinical challenge worldwide. In such situations, the application of biomaterials is necessary for filling defects and promoting bone regeneration. Bone repair biomaterials having osteoconductive and osteoinductive properties can act as an appropriate template for the formation of new bone and induce the osteogenic differentiation of preosteocytes and stem cells. Thus, the influence of biomaterials on the regulation of osteogenesis of mesenchymal stem cells (MSCs) has been widely studied. However, immune response is also critical in bone healing; macrophages play pivotal and dynamic roles in bone regeneration. The interfacial properties of biomaterials that affect the adsorption of proteins and the adhesion function of cells require great attention in the field of bone tissue engineering because they are related to the crosstalk with the immune and bone or stem cells. Thus, selection of biomaterials or specific surface coatings may reduce local undesirable inflammatory responses and promote bone regeneration. This review provides a detailed overview of bone regeneration mechanisms and the interaction between immune cells and MSCs. Moreover, the influence of biomaterials on the regulation of functions of MSCs and macrophages and the macrophage-related inflammatory response triggered by biomaterials and its specific role in osteogenesis are discussed.
\end{abstract}

\section{Introduction}

Traumata and degeneration of skeletal tissues, such as bone, cartilage, ligament, and tendon, are among the most frequent clinical problems and often require the use of implants or grafts to restore their function [1]. Although bone exhibits good recovery and regeneration potential, impaired bone healing after trauma or tumor resections is extremely common $[2,3]$. Thus, surgical interventions are required for healing large bone defects, which are challenging in orthopedic medicine [4]. Because of their osteogenic, osteoinductive (capable of recruiting immature cells and stimulating them to develop into preosteoblasts), and osteoconductive (the ability to support bone growth on its surface) abilities, autologous bone grafts have been considered the gold standard in clinical approaches for treating bone defects [5]. However, grafts have several flaws and disadvantages, such as limited tissue availability, pain, and donor-site morbidity [6]. Although allogenic bone grafting can be an alternative, it has several limitations, including suboptimal osteoactivity, donor incompatibility, and an increased risk of disease 
transmission, compared with autografting [4]. Therefore, new approaches, such as the use of biomaterials and tissue engineering, have emerged to augment the natural healing capacity of bone. Actually, the primary healing mechanism in the regeneration of large bone defects is bone ossification, which is controlled by various inductive factors and the recruitment of inflammatory cells involved in the regulation of osteoprogenitor cell activities and bone remodeling [7]. Therefore, new strategies capable of creating a natural bone healing environment emerge as a promising approach for the regeneration of biologically functional bone tissues.

It was once believed that only two types of cells, namely, osteoblasts and osteoclasts, are involved in the process of bone healing, which play essential roles at different time stages and locations [8]. Osteoblasts originating from mesenchymal stem cells (MSCs) are the predominant bone-forming cells [9], whereas osteoclasts are a type of multinucleated cells derived from monocytes, which are responsible for bone resorption [10]. Currently, it is well accepted that the complex interplay of cells, including MSC-osteoblasts and monocyte-macrophage-osteoclast lineage, is pivotal in the formation, remodeling, and repair of tissue [11]. Therefore, it is essential to create a bone healing microenvironment considering the importance of the strong crosstalk between the skeletal and immune systems.

Over the last few decades, the advancement of tissue engineering, particularly the improvement in biomaterials, has been largely propelling the development of bone tissue regeneration [12]. Nevertheless, growing evidence suggests that the physical and chemical properties of biological materials influence local tissue inflammatory response, which positively or negatively affects osteogenesis [13]. For example, Reifenrath and coworkers found that the implantation of screws composed of the magnesium alloy ZEK 100 caused a higher inflammatory response accompanied by a larger bone volume loss than $\mathrm{MgCa} 0.8$ screws [14]. However, Wang et al. found that calcium phosphate ceramics promoted the secretion of inflammatory cytokines and growth factors from macrophages, which enhanced osteogenesis [15]. Several other studies proved that biomaterials could affect the osteogenesis of stem cells by regulating macrophage activation [16]. Hence, in the field of bone tissue engineering, great attention should be paid to the interfacial properties of biomaterials to adjust their crosstalk with the immune cells in order to effectively reduce local undesirable inflammatory responses and promote bone regeneration.

In this review, we first provide a general overview of the bone regeneration mechanisms and the interaction between immune cells and MSCs. Further, the influence of biomaterials on the regulation of the biological behavior as well as the function of macrophages and MSCs is emphasized. In addition, the macrophage-related inflammatory response triggered by biomaterials and its specific role in osteogenesis is discussed.

\section{The Composition and Healing Mechanism of the Bone}

Bone is the main component of the musculoskeletal system, which plays a pivotal role in the support, protection, and motion of the body. Mature bone is composed of minerals ( $\sim 65 \%$ by weight), organic matrix ( $10 \%)$, and water $(\sim 25 \%)$ [17]. The inorganic bone matrix accounts for $99 \%$ of the calcium, $85 \%$ of the phosphorous, and $40 \%-60 \%$ of the magnesium and sodium of the body's storage [18]. Inorganic matrix mainly exists in the form of hydroxyapatite and provides the majority of bone strength, including stiffness, and resistance to compressive forces [18]. Its removal renders bone soft, malleable, and spongy, for example, osteomalacia or Rickets secondary to vitamin D deficiency [19]. Although the organic matrix secreted by osteoblasts predominantly comprises type I collagen, it also contains proteoglycans, glycoproteins, and growth factors [18]. These growth factors include the bone morphogenic proteins (BMPs) and other transforming growth factors, family factors, interleukin-1, interleukin-6, osteocalcin, osteonectin, and bone sialoprotein $[20,21]$. These factors play important roles in osteogenesis as well as mineralization and remodeling of bones [21]. Organic matrix gives bone its form and provides resistance to tensile forces. One of the important components of the bone matrix essential for the remodeling and regeneration of bone is BMPs, which were discovered in 1965 by Urist [22]. BMPs are members of the transforming growth factor superfamily, which include 20 known members. Embryologically, they are important mediators of cardiac, nerve, and neural crest development and possess critical osteoinductive properties applicable in postnatal bone formation and healing.

Osteogenesis is a key process during bone regeneration and remodeling [23]. In this process, osteoblasts emerge from the differentiation of osteogenic progenitor cells in the periosteum and are responsible for the synthesis and mineralization of bone during initial bone formation and later bone remodeling [24, 25]. Osteoblastogenesis, that is, the differentiation of osteogenic cells such as MSCs into osteoblasts, requires a certain microenvironment and is regulated by an interplay of cytokines, components, and mechanical characteristics of the matrix [26]. Osteoblasts are eventually surrounded by the growing bone matrix; as the matrix calcifies, the cells get trapped in it and become osteocytes, that is, bone cells $[27,28]$. The extracellular matrix (ECM) proteins can interact with cells via integrin adhesion receptors [29] that are involved in cell signaling transduction, thus influencing the attachment, proliferation, and differentiation of cells [30]. Moreover, ECM proteins bind to soluble growth factors, including BMPs, and regulate their distribution, activation, and presentation to cells, which integrate complex, multivalent signals to cells in a spatially organized and regulated manner [31,32]. More recently, it has been demonstrated that mechanical characteristics of the matrix, including stiffness and deformability, also provide inputs into cell behavior $[33,34]$. 
The regeneration of bone tissue after injuries is also inseparable from the interplay with the immune system. Bleeding after bone injury results in the delivery of different type of blood cells such as platelets and granulocytes as well as blood monocytes to the injury site. Monocytes then differentiate into macrophages under the effect of cytokines (M-CSF, IL-4, etc.) that are present in the wound area. In the early phases of bone regeneration, M1 macrophages mediate acute inflammation, regulate MSCs recruitment, and initiate bone tissue regeneration [35]. The initial inflammation can induce the recruitment of MSCs and immune cells, including monocytes [36]. Subsequently, the recruited macrophages may positively regulate the differentiation of MSCs into osteoblasts by secretion of cytokines, including IL-6 and TNF- $\alpha$ [36]. However, for prolonged inflammation, the remaining proinflammatory cytokines negatively affect bone regeneration [37].

\section{Role of Macrophages in Bone Regeneration}

Inflammation is a complex defensive process of the body reflecting its response to various noxious stimuli. Immune cells, such as neutrophils, monocytes, macrophages, T cells, and dendritic cells, play an important role in the regulation of the immune response against infections and injuries [38]. Various types of immune cells are involved in the inflammatory response; however, macrophages are indispensable and key players because they secrete various cytokines that control inflammation and participate in tissue regeneration [39]. Macrophages are grossly classified as the following phenotypes: inflammatory macrophages (M1) and anti-inflammatory macrophages (M2) [35]. M1 phenotype is the "classically activated" subset of macrophage, whereas M2 phenotype is known as "alternatively activated" macrophages owing to differing activation signals compared with the M1 subset [40]. M1 macrophages secrete proinflammatory cytokines such as IFN $\gamma, \mathrm{TNF} \alpha$, and IL-6, which affect osteoblasts by inhibiting their differentiation and promoting apoptosis, thus hindering the production of collagen by osteoblasts, which is necessary for mineralization [37]. In contrast, M2 macrophages produce TGF- $\beta$, VEGF, and IL-10, which inhibits osteoclast formation and supports bone deposition $[37,41]$. A fine balance in M1/M2 macrophage function appears mandatory to fracture healing and successful regeneration. Indeed, macrophages play essential roles not only in early inflammation but also in the later phase of bone healing, which relies on the M1/M2 macrophage phenotype switch [42]. M1 macrophages are necessary for the initiation of the regeneration process; however, prolonged infiltration of proinflammatory macrophages causes chronic inflammation and negatively influences bone healing $[43,44]$. A key element in bone healing is the shift from the proinflammatory M1 macrophage, important during the initial healing step, to the anti-inflammatory M2 phenotype, during stages in which endochondral ossification is expected [42]. In addition, macrophages phagocytose necrotic and apoptotic cells and recruit MSCs to the injured site to promote osteogenesis [45]. In this context, increasing attention has been paid to the role of macrophages in tissue regeneration.
Osteoclasts are usually regarded as the "resident macrophages" of bone. However, a recently identified resident population of nonosteoclast macrophages in the skeleton has been found to play diverse roles in bone biology. It was found that they participated in bone formation and regulated bone homeostasis [46]. Nicolaidou et al. demonstrated that monocytes and macrophages facilitate mineralization. More specifically, monocytes induced osteogenesis in MSCs through the STAT3 activation [47]. Additionally, oncostatin $\mathrm{M}$ (OSM) secreted by macrophages has been considered a specific macrophage factor that supports the osteoblastic potential of MSCs [48]. Further evidence of the ability of macrophages to support mineralization has been verified by the increased mineral deposition when vascular smooth muscle cells were cocultured with macrophages [49]. Moreover, the importance of macrophages in bone healing has been demonstrated in different animal models [34]. For example, Wang et al. have found that magnesium-calcium phosphate cement upregulated the bone-repair-related release of the cytokine TGF- $\beta 1$, downregulated proinflammatory cytokines, including TNF- $\alpha$ and IL-6, and facilitated bone healing [50]. Mice treated with a broadspectrum promyeloid factor, namely, macrophage colonystimulating factor (CSF-1), showed an increase in bone formation and bone mass [51-53]. Zhu et al. found that crocin induced polarization of anti-inflammatory (M2) macrophage and promotion of cocultured BMSCs' osteogenic differentiation [54]. In addition, a recent study has indicated that macrophage deficiency hindered the regeneration of the tail fin and patterning of bony rays in zebrafish [55].

\section{Role of MSCs in Bone Regeneration}

MSCs can both self-renew and self-differentiate. A wide variety of MSCs, including BMSCs, adipose-derived stromal cells (ADSCs), and umbilical cord mesenchymal stromal cells (UC-MSCs), exist. BMSCs are considered the progenitor cells for bone formation; they can differentiate into multiple cell types, such as osteoblasts, chondrocytes, adipocytes, and smooth muscle cells [56-58]. Previous studies have demonstrated that BMSCs play an essential role in the maintenance of bone homeostasis and the treatment of various bone disorders $[59,60]$.

The proficient recruitment of MSCs to the defect site is a critical process during bone regeneration [61]. Chemotactic factors released by macrophages at the bone defect site play a critical role in MSC homing and recruitment. It is known that MSCs express at least 19 chemokine receptors, such as CXCR1 and CCR1 [62]. Local hypoxia in the initial stage of fracture is caused by vascular disruption and induces the production of chemotactic factors, including stromal cellderived factor-1 (SDF-1 and CXCL12), which in turn promotes the chemotactic recruitment of numerous cell types, such as MSCs and other progenitor cells $[63,64]$, thus facilitating bone regeneration [65]. MSCs can also recruit other MSCs or progenitor cells to the injury site via paracrine action such as stromal cell-derived factor 1 [66]. Therefore, several attempts have been made to stimulate the 
recruitment/mobilization of stem cells for accelerating bone regeneration. For example, stromal-derived factor 1 (SDF-1) induced stem cell mobilization and homing [67]. The local delivery of SDF-1 to bone injury sites during bone defect healing can recruit MSCs/precursor cells, which results in tissue-specific differentiation and significant bone regeneration [68]. A similar study demonstrated that cobalt contributes to the recruitment of MSCs because it activates HIF- $\alpha$, which then accelerates the bone healing process [69]. Moreover, the recruitment of MSCs for efficient tissue regeneration is largely affected by the local microenvironment. The chemical, topographic, and mechanical properties of the ECM have been widely investigated to study their influence on attachment, migration, and differentiation of MSCs [70].

The osteogenic differentiation potential of MSCs is also of great importance for bone regeneration. Multiple intermediate processes involved in the differentiation of MSCs into cells of osteogenic lineage are important targets for cytokines, hormones, and ECM, thereby regulating bone regeneration. For instance (Figure 1), a large number of signaling pathways have been found to induce conversion between osteogenesis and adipogenesis of MSCs, which is primarily related to the following two key transcription factors: Runx2 (the key modulator of osteogenic differentiation) and PPAR (the master regulator of adipogenic differentiation) [71]. The presentation of growth factors, such as BMP-2, TGF- $\beta 1$, and FGF2, to MSCs, has been found to target Runx2 and to activate and regulate osteogenesis [72-74]. In addition to proosteogenic effects, the supply of Nel-like protein type I (NELL-1) significantly reduced adipose differentiation of ADSCs while promoting osteogenic differentiation [75, 76]. Moreover, the recently discovered transcriptional activator with PDZ-binding motif (TAZ) is another critical transcriptional modulator capable of stimulating osteogenesis while simultaneously blocking the differentiation of MSCs into adipocytes [77]. It is noteworthy that the mechanical signals transduced from the cellular microenvironment (substrate topographical, stiffness, etc.) can affect the cell fate determination of MSCs via YAP/TAZ activity regulation [78]. Experiments have demonstrated that YAP/TAZ localizes outside the nucleus and are inhibited when cultured on a soft matrix, whereas it localizes in the nucleus and is transcriptionally active when cells are cultured on a stiff matrix [79]. Moreover, YAP/TAZ is inhibited when cells are restricted to small adhesive areas $[79,80]$.

\section{Crosstalk between MSCs and Macrophages and Its Role in Bone Regeneration}

Recent studies have revealed a clear understanding that successful bone healing is based on a carefully coordinated crosstalk between macrophages and MSCs in the body (Figure 2(a)) [81]. Particularly, responses of the innate immune system can affect the formation, remodeling, and healing of bones, and this process is quite complex [82]. Among the variety of immune cells, macrophages play a significant role in the regulation of bone repair [83]. Previous studies have demonstrated that inflammatory macrophages, which secrete TNF- $\alpha$ and IL- $1 \beta$, suppressed osteoblastogenesis [84]. In contrast, other studies suggested that several foreign materials result in an M1-dominant macrophage phenotype, which enhances bone formation and healing $[85,86]$. Consistent with in vivo studies, the in vitro studies also showed the positive effect of M1-dominant macrophages on strengthening osteogenic differentiation of MSCs [87]. Omar et al. found that MSCs treated with conditioned media (CM) containing lipopolysaccharide(LPS-) stimulated monocytes exhibited an enhanced osteogenic differentiation (see Figure 2(b)) [88]. In addition, it was demonstrated that M1 macrophages were capable of secretion of OSM, which promoted the osteoblastogenesis of MSCs in vitro [48]. Conversely, other studies reported that M2, but not M1, macrophages enhanced osteogenic differentiation of MSCs [89]. Indeed, M1 versus M2 alternatively activated macrophages, which played key roles in successful osteogenic differentiation and bone repair. M2 phenotypes can be attributed to a properly regulated inflammatory response being an important physiological process that promotes tissue repair after injury [81]. However, the exact role of the M1/M2 paradigm in response to osteogenic differentiation of MSCs is still not completely understood. More recently, several studies have implicated that M1 and M2 dominant macrophages cooperatively regulate the osteogenic differentiation of MSCs. More specifically, M1 macrophages enhanced osteogenic differentiation at an early stage through the recruitment of stem cells to injured sites, whereas M2 macrophages may subsequently facilitate matrix mineralization (Figure 2(c)) [90].

Macrophage-derived osteoclasts are also important for the regulation of MSC-based bone regeneration. Quint and Pederson et al. found that cytokines (BMPs, WNTs, Sphingosine 1-phosphate, etc.) secreted by osteoclasts induced the migration and osteogenic differentiation of MSCs [91, 92]. Another notable research showed that MSCs transplanted with biphasic calcium phosphate (BCP) attracted circulating monocytes and induced their differentiation into osteoclasts and promoted osteogenesis. Interestingly, local injection of clodronate or anti-RANKL antibodies (a key factor for osteoclast differentiation and activation) abolished osteoclasts formation and suppressed osteogenic differentiation. This fact has reemphasized the considerable role of osteoclasts in MSC-mediated osteogenic differentiation and bone formation [85]. Overall, these studies demonstrated that macrophage polarization is of great importance for distinct roles in the bone regeneration mediated by MSCs, which is similar to the repair process of the normal tissue (from a proinflammatory to a preoperative stage).

MSCs can modulate immune cells through cell contact by binding to receptors on the surface of immune cells $[93,94]$ and secretion of cytokines, including TGF- $\beta$, hepatocyte growth factor, and prostaglandin E2 (PGE2), as well as other anti-inflammatory factors $[95,96]$, and have a pivotal role in maintaining immune homeostasis [97]. Previous investigations on the immunomodulatory function of MSCs have been concentrated on the interaction between MSCs and B lymphocytes, dendritic cells, and natural killer 


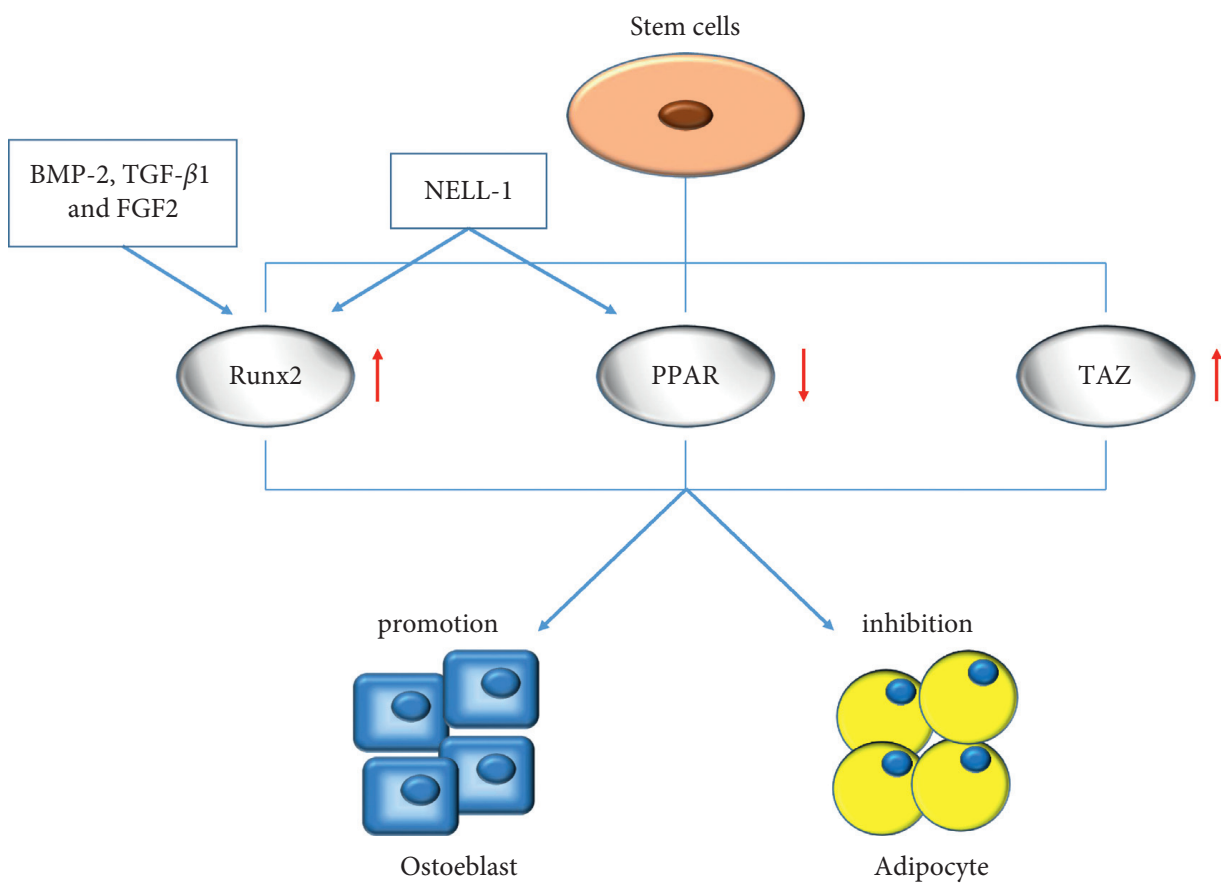

FIGURE 1: Schematic representation of signaling pathways which induce the switch between osteogenesis and adipogenesis in MSCs.

cells [98]. In recent years, the use of MSCs in the repair of damaged tissues and modulation of the inflammatory response has gained increasing attention with respect to macrophage regulation. MSCs have the ability to differentiate into osteoblasts and their immunomodulatory action affects osteogenesis [99]. The mixing of MSCs with BCP particles enhanced the recruitment of macrophages to the site of BCP implantation and accelerated bone regeneration $[85,86]$. Moreover, it was observed that the production of inflammatory cytokines, including TNF- $\alpha$, IL-6, IFN- $\gamma$, and IL-12p70, by bone marrow-derived macrophages cultured with MSCs or in MSC-conditioned medium was significantly suppressed after stimulation with TLR7/8 ligand (the most potent activator of monocytes) [100]. Simultaneously, the production of anti-inflammatory cytokines, including IL-12p40 and IL-10, increased. Interestingly, recent studies found that exosomes secreted by MSCs not only promoted tissue repair but were also involved in the regulation of inflammatory responses. Although the MSC-derived exosomes could enhance the enrichment of CD163+ M2 macrophages, they reduce the infiltration of CD81+ M1 macrophages and thus decrease the release of related inflammatory factors (Figure 2(d)) [101]. Several studies demonstrated that allogeneic MSCs could induce the differentiation of monocytes toward an anti-inflammatory M2 phenotype, which may occur through the STAT-3 and NF$\kappa \mathrm{B}$ pathways $[102,103]$. Furthermore, MSCs can be polarized into either a proinflammatory or immunosuppressive phenotype based on Toll-like receptors. They are polarized into a proinflammatory phenotype by TLR 4 stimulation and into an immunosuppressive phenotype by TLR3 stimulation, which is determined by MSC1 and MSC2, respectively [104].

\section{Role of Biomaterials in the Regulation of Macrophage Behavior}

Biomaterials have a long record of replacing lost or damaged tissues and supporting the healing process [105]. To date, various polymers [106], ceramics [107], and metals [108] have been applied as implant materials to replace and regenerate damaged tissues. When a biomaterial is implanted in the body, it leads to an extensive and complex inflammatory response related to the surgical intervention and the properties of material, which recruits various types of immune cells to the region of the implanted biomaterial by triggering a series of biochemical signals [109]. Thereafter, owing to stimulation by various proinflammatory cytokines produced by other inflammatory cells, including mast and dendritic cells, the recruited monocytes can differentiate into macrophages, which adhere to the implanted biomaterials and subsequently affect the bone healing process [109]. In this process, the biophysical and biochemical properties of the biomaterials play a crucial role in directing the phenotypic transformation of macrophages [110]. The inflammatory response is related to the proteins adsorbed on the implanted materials which formed a provision matrix at the biomaterial's surface [111]. For example, the amount of adsorbed vitronectin and fibronectin on the implant surface is pivotal for monocyte adhesion and giant cell formation via their integrin-mediated interaction with these proteins $[112,113]$. Additionally, the provision matrix contains and releases several other cytokines and GFs of diverse nature that are capable of modulating the attraction and activity of macrophages and other immune cells [111]. The properties of the biomaterials can strongly influence the adsorption of proteins in terms of types, concentration, mode, and 


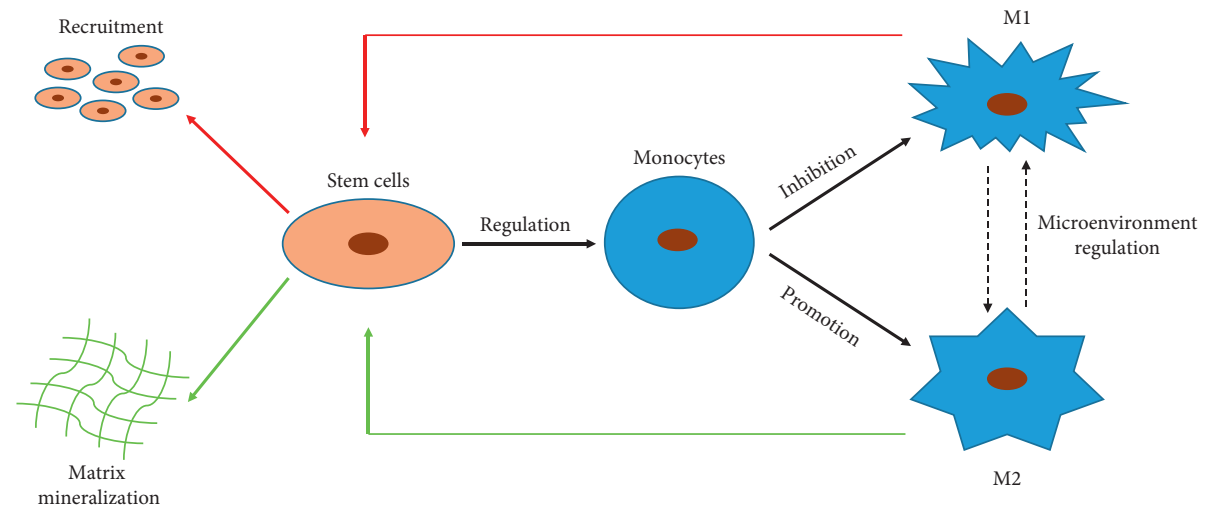

(a)

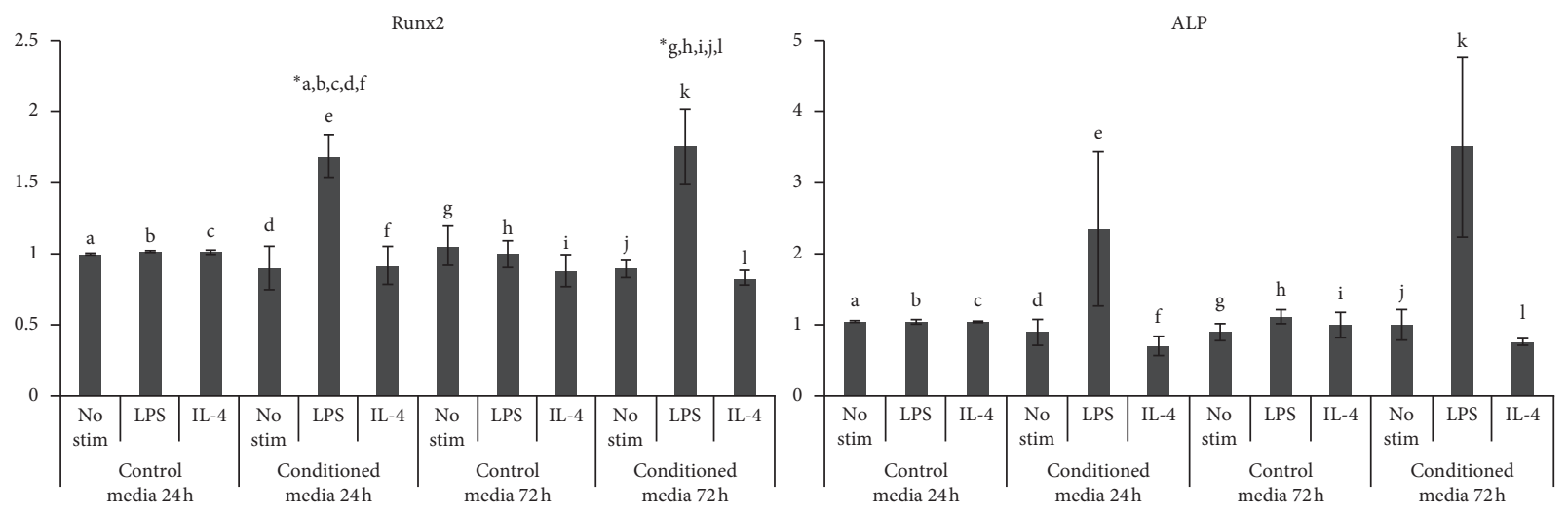

(b)
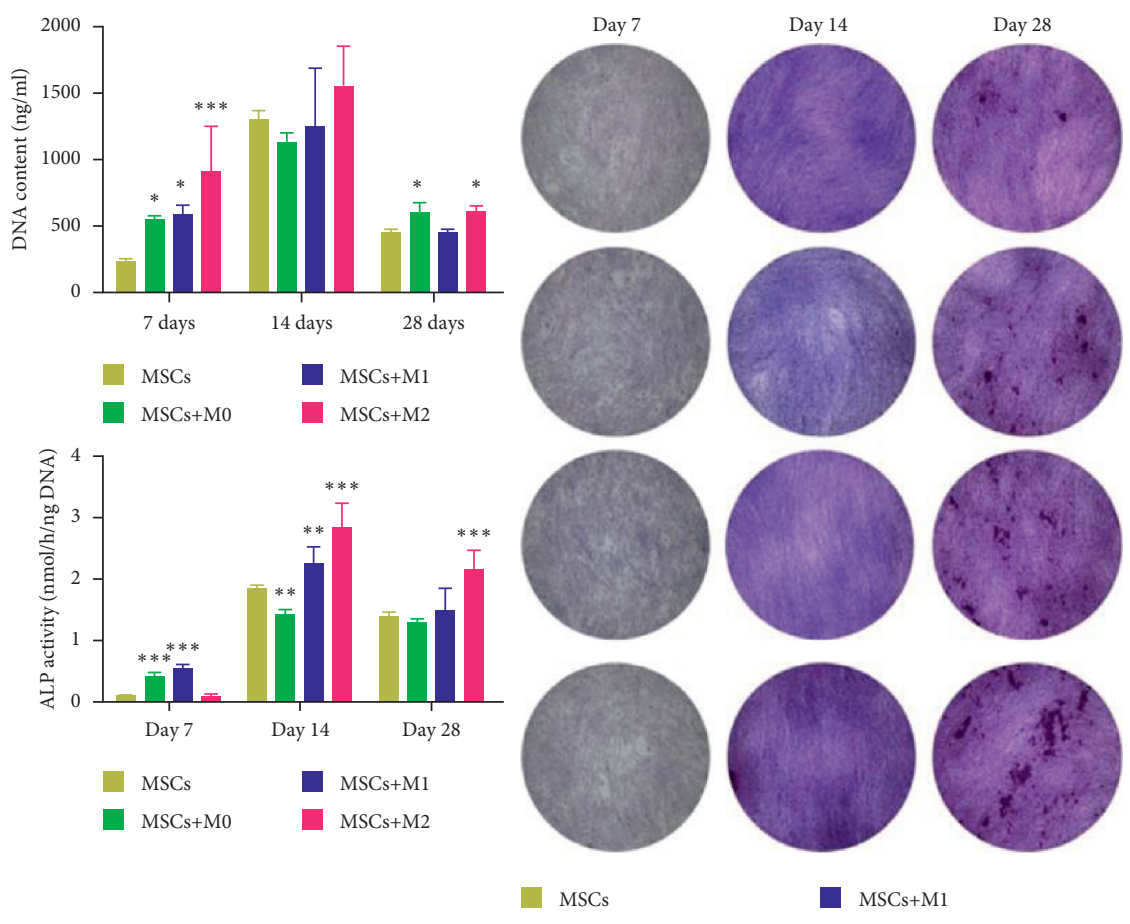

MSCs+M0

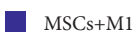

(c)

Figure 2: Continued. 

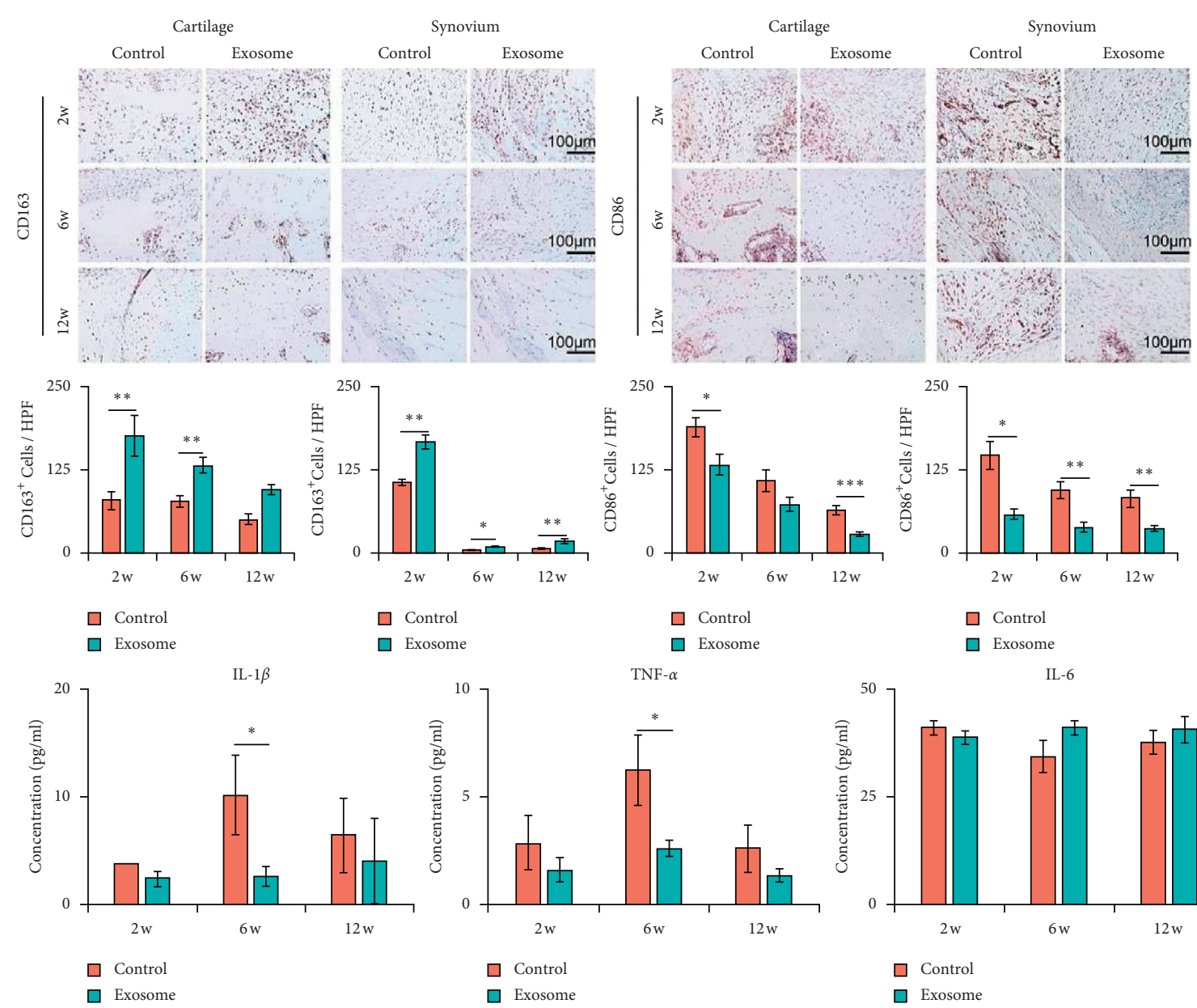

TNF- $\alpha$

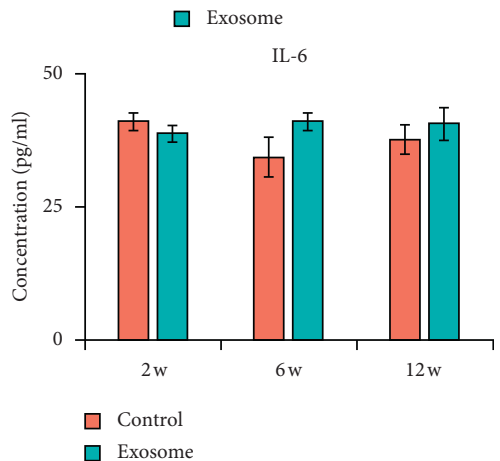

(d)

FIgURE 2: (a) The schematic diagram indicating the crosstalk between MSCs and macrophages. (b) The relative gene expression of Runx2 and ALP in MSCs. Gene expression of Runx2 and ALP in hMSCs after culturing in unconditioned control media (Ctrl) or monocyte conditioned media (CM) for $72 \mathrm{~h}$ [88] (Copyright 2011, Elsevier). (c) Proliferation and ALP activity of MSCs indirectly cocultured with M0, M1, and M2 macrophages [90] (Copyright 2017, Springer). (d) Effects of MSC exosomes on macrophage infiltration and proinflammatory cytokine production during cartilage repair [101] (Copyright 2018, Elsevier).

conformation [114]. Moreover, it was observed that the physical properties of biomaterials, such as surface topography, stiffness, and porosity, are key factors for regulating macrophage polarization [115]. Hamlet et al. proved that the secretion of the proinflammatory factor IL-6 increased in M1-dominant macrophages cultured on Ti, which exhibited microroughness [116]. Thus, it became evident that the microroughness of the biomaterial promoted the secretion of inflammatory factors, triggering both the M1 and M2 phenotypes. Moreover, the pattern of the surface, such as the diameter and alignment of fibers, influences the activation of macrophages. The aligned poly (L-lactic acid) (PLLA) fibers with micro- or nanoscale diameter enhanced macrophage adhesion compared with randomly aligned or flat PLLA. In the presence of LPS stimulation, the secretion of inflammatory cytokines was significantly less in macrophages cultured on fibrous PLLA than those cultured on flat PLLA films, indicating that fibrous materials reduce classical activation in macrophages [117]. Substrate stiffness and applied forces on substrates also affect macrophage activation. In the presence of LPS stimulation, murine macrophages showed increased expression of TNF- $\alpha$, IL-10, IL- $1 \beta$, and IL-6on poly (ethylene glycol) hydrogels with higher stiffness [118]. Pores in scaffolds also play a key role in tissue engineering applications because they allow permeation of the scaffold with oxygen, nutrients, and even proteins. However, the size of the pores and porosity of scaffolds are considerable factors that affect immunomodulation and osteogenesis because cells interact differently with environments in nano-, micro-, and macroscale materials [119]. Sussman et al. investigated the influence of microsized pores on macrophage polarization phenotypes using poly (methyl methacrylate) (PMMA) and poly (2-hydroxyethyl methacrylate) (pHEMA) scaffolds. Implants with pore sizes of $34 \mu \mathrm{m}$ increased the levels of IL-1R1 and inducible nitric oxide synthase (iNOS) (M1 phenotype marker) upon 
implantation into mice [120]. Conversely, it was found that the morphology of macrophages was strongly regulated by micropatterned substrates. More specifically, the macrophages that were forced into an elongated morphology because of the surface structures showed greater M2dominant polarization (Figure 3(a)) [121]. Additionally, the chemical composition of biomaterials affects protein adsorption as well as differentiation and activity of macrophages, which regulates the inflammatory response [115]. Accordingly, it was found that the characteristics of biomaterials related to the presence of specific functional groups, such as the surface charge and wettability, played a key role in the inflammatory reaction [109]. Self-assembled monolayers with different wettability and charge properties were used as model biomaterials for macrophage/fibroblast coculturing. It was demonstrated that the hydrophobic $\mathrm{CH} 3$ surface caused the strongest inflammatory reactions, whereas the hydrophilic/anionic $\mathrm{COOH}$ surface caused the least inflammatory response (Figure 3(b)) [122]. They also found that the surface coating of glycosaminoglycans (GAGs) and chitosan (Chi) composed polyelectrolyte multilayers, particularly the heparin-Chi multilayers, and strongly reduced the inflammatory responses [123]. Conversely, polyethylene terephthalate films with hydrophilic/ neutral surfaces promoted macrophage activation, which generated markedly high amounts of different cytokines and chemokines [124]. In addition, a carbon nanotube-covered surface that was modified by plasma polymerization with oxygen-containing functional groups and the chemical properties of oxygen groups enhanced the adhesion and activation of macrophages, resulting in polarization to M1 phenotype [125]. Therefore, the dynamic interactions between biomaterials and immune cells have attracted increasing attention in the field of tissue engineering.

\section{Role of Biomaterials in the Regulation of MSC Behavior}

Indeed, the modulation of cellular adhesion is important for the control of recruitment in the early stage osteogenic differentiation of stem cells [126]. However, most man-made biomaterials lack favorable surfaces for cell attachment owing to missing specific cell-recognizable signals, such as adhesive ligands for integrins [127-129]. Additionally, chemical composition and surface properties greatly affect the regulation of protein adsorption and subsequent cell attachment and differentiation [126, 130, 131]. Therefore, surface functionalization of implant materials has emerged as a promising method to obtain an interface with enhanced bioactivity between implants and tissues [127, 132].

ECM includes proteins such as fibrillar collagens and elastin as well as adhesive proteins such as fibronectin (FN) and proteoglycans (e.g., aggrecan). ECM components have been widely used to create a bioactive interface owing to the excellent biological properties of ECM, which can offer a suitable microenvironment and provide significant cues for the adhesion, migration, and differentiation of MSCs [133]. Lee et al. engineered FN type III 9 and 10 domains fused to elastin-like polypeptides (FN-ELPs). The recombinant MSCs cultured on plates coated with FN-ELP had significantly greater adhesion activity, proliferation, and osteogenesis than the cells cultured on noncoated plates [134]. Vitronectin and FN are the frequently studied proteins that enhance cell attachment because they are selectively recognized by the cell transmembrane receptors integrins owing to the presence of the "RGD" (Arg-Gly-Asp) amino acid sequence [135]. Hence, the RGD sequence has been frequently used to modify biomaterial surface. For example, investigations have revealed that immobilized RGD peptides can significantly promote the adhesion of hBMSCs. In addition, it was shown that peptide density and the spacing between clusters of RGD peptides could determine integrin receptor binding and subsequent signal transduction, which was visualized by the expression of focal adhesion of stem cells [136]. We have previously shown that the formation of polyelectrolyte multilayers using bone matrix components, namely, collagen I (Col I) and chondroitin sulfate (CS), has a superior effect on promoting the adhesion and osteogenic differentiation of hADSCs compared with a combination of collagen I with hyaluronan that is not found in bone (Figures 4(a) and 4(b)) [137]. In addition to ECM proteins, growth factors have been frequently applied for making biomaterials bioactive toward cells, including the support of the differentiation of MSCs. It was reported that self-assembled, microsphere-incorporated hMSC sheets could form cartilage in the presence of exogenous transforming growth factor $\beta 1$ (TGF- $\beta 1$ ) or with TGF- $\beta 1$ released from incorporated microspheres. Moreover, improved cartilage formation was found in the microsphere-incorporated cell sheets [138]. Zhang et al. prepared poly (lac-tic-co-glycolic acid) (PLGA) microspheres coated with multilayer polyelectrolytes ((HA-CS)2-Hep-BMP-2-Hep-(CS-HA)2) as the multibarrier microcarriers for osteogenic growth peptide and BMP-2. The immobilization of the microspheres at the surface of a highly interconnected porous hydroxyapatite (HAP) scaffold largely promoted in vitro and in vivo osteogenic differentiation (Figure 4(c)) [139]. In a study by Wang et al., hydroxyapatite ( $\mathrm{HAP}) / \mathrm{TiO}_{2}$ composite coatings were first prepared on titanium (Ti) surface by one-step microarc oxidation; next, pure Chi and bone morphogenic protein-2- (BMP-2-) encapsulated CS coatings were loaded on the $\mathrm{HA} / \mathrm{TiO}_{2}$ surfaces, which accelerated the adhesion, migration, and proliferation of osteoblastic cells [140].

Topographical cues are other features of biomaterial surface that can modulate the morphology and subsequently cellular functions, such as cytoskeletal organization, gene, and protein expressions of MSCs [141]. Seunghan et al. altered the dimensions of titanium oxide surface nanotubes and observed that small (30 $\mathrm{nm}$ in diameter) nanotubes promoted adhesion without noticeable differentiation, whereas larger (70-100 $\mathrm{nm}$ in diameter) nanotubes elicited a significant hMSC elongation (10-fold increased). The latter induced cytoskeletal stress and selective differentiation into osteoblast-like cells [142]. Kim and coworkers found that hDPSCs presented a linear arrangement on a nanopatterned surface and irregular arrangement on a conventional surface, which was accompanied by a more significant adipogenic differentiation. However, gene expression analysis 

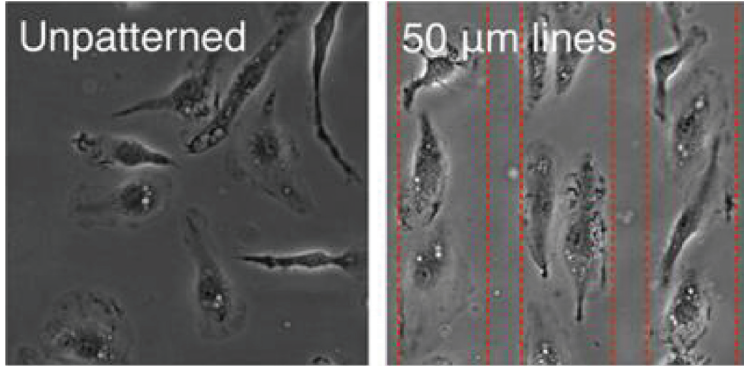

(a)
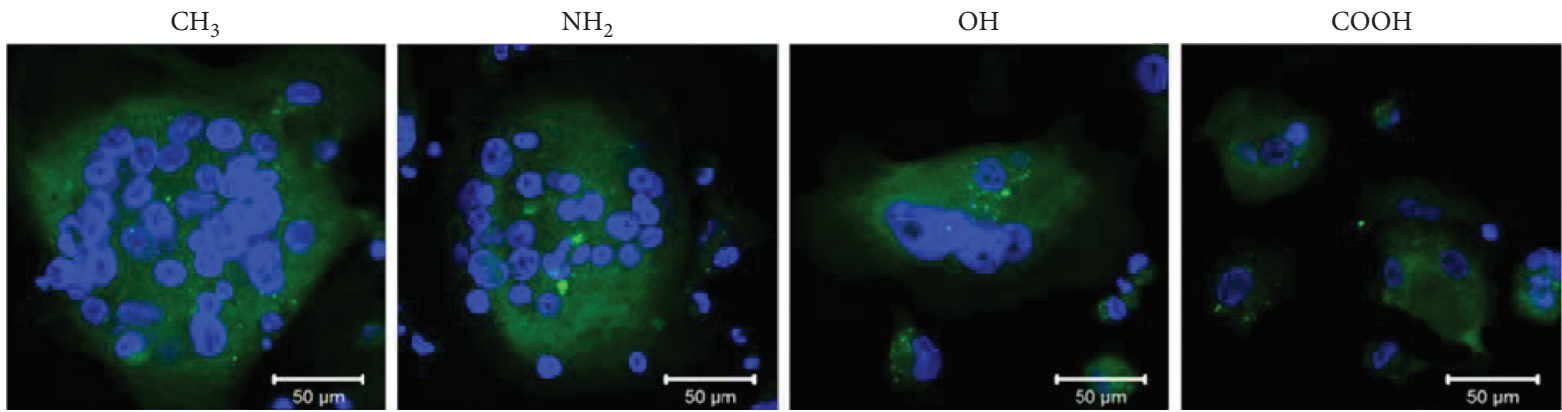

(b)
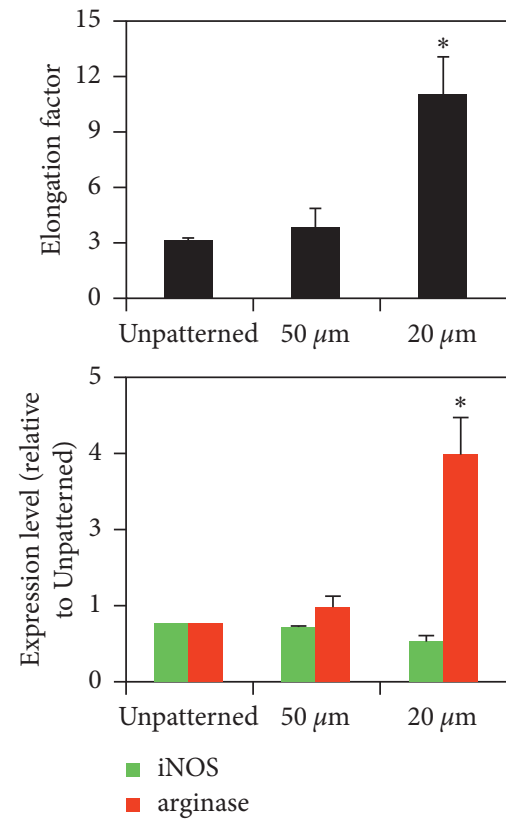

(c)

Figure 3: (a) The elongation of cells by micropatterning drives macrophage polarization [121] (Copyright 2013, National Academy of Sciences). (b) Expression of $\beta 1$ integrin was determined by fusing macrophages/FBGCs in macrophage monocultures at $\mathrm{CH}_{3}, \mathrm{NH}_{2}, \mathrm{OH}$ and COOH surfaces [122] (Copyright 2015, Elsevier).

revealed significantly higher expression of LPL in the nanopatterned group than in the conventional group after induction of osteogenic differentiation [143]. Dalby et al. presented the topographies, originally produced by colloidal lithography and polymer demixing on silicon and then embossed (through an intermediate nickel shim) into polymethyl methacrylate, which stimulated the osteoprogenitor cell differentiation toward an osteoblastic phenotype (Figure 4(d)) [144].
In addition to topographical cues, it has been evidenced that stiffness and elasticity of the surrounding matrix have profound effects on the regulation of MSCs fate [145]. For example, Rowlands and George's groups have demonstrated the importance of stiffness and ECM protein microenvironments by culturing MSCs on polyacrylamide gel substrates (with varying stiffness) coated with tissue-specific ECM proteins. The gel-protein substrates supported the proliferation of MSCs in a stiffness-dependent manner. 


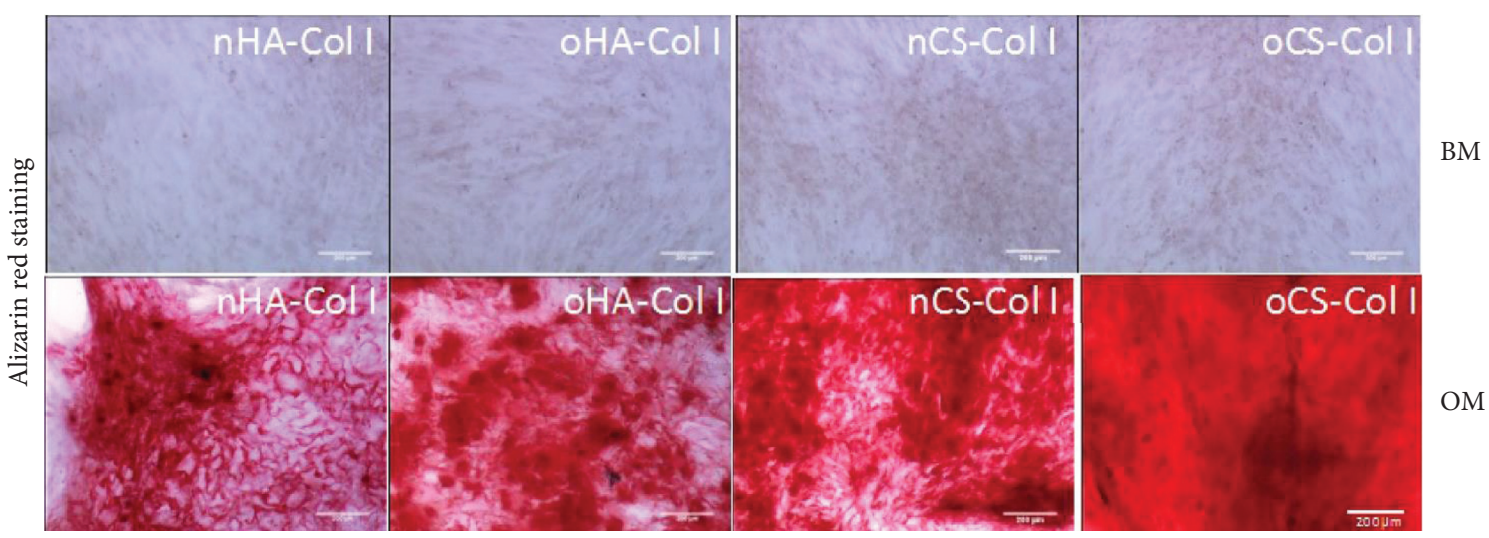

(a)

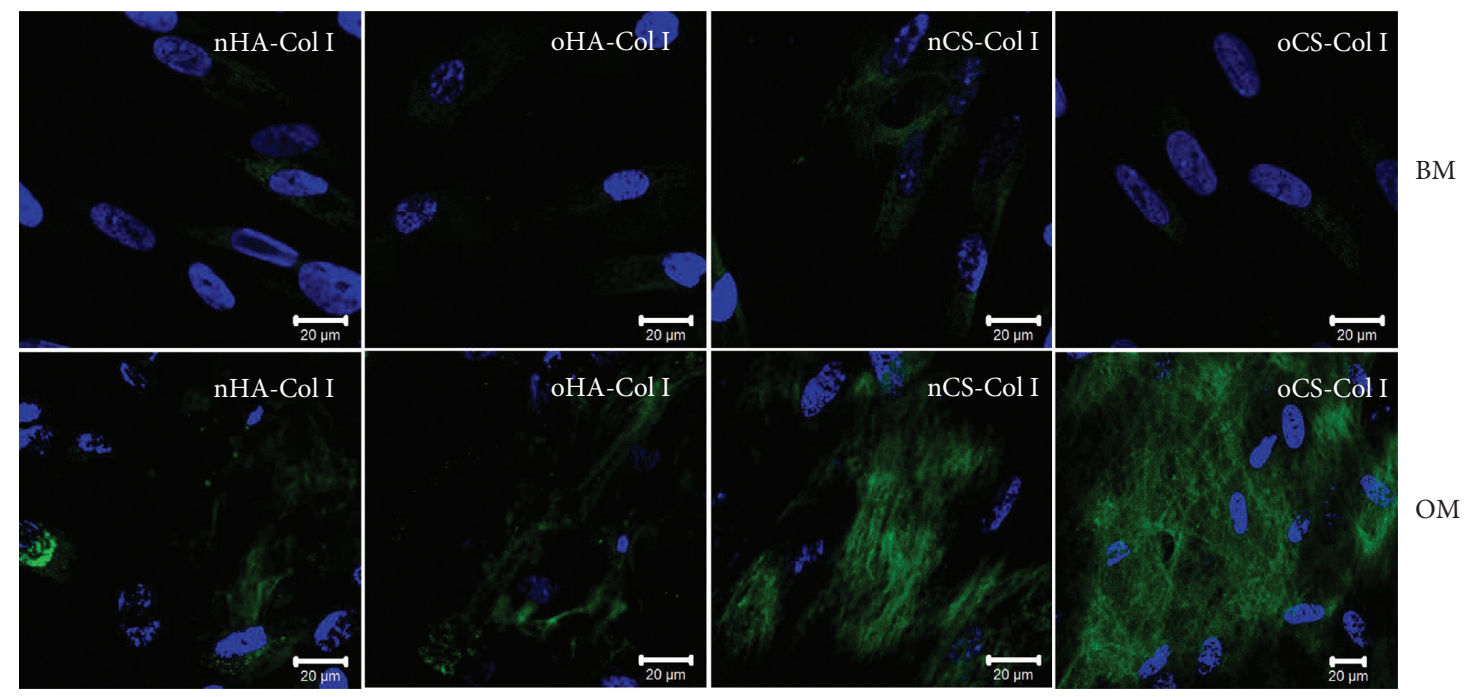

(b)

Figure 4: Continued. 
Actin

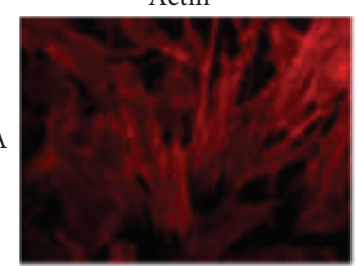

PMs (OGP/BMP-2)-HA

PMs (OGP)-HA
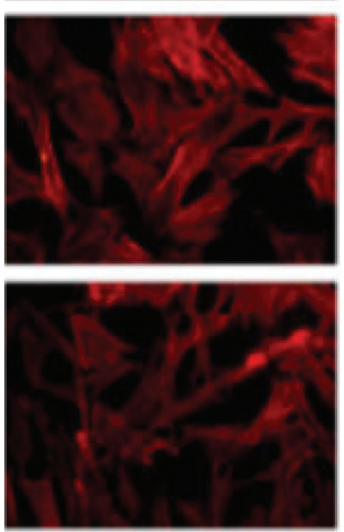

PMs (BMP-2)-HA

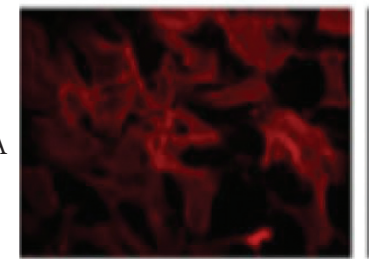

OCN
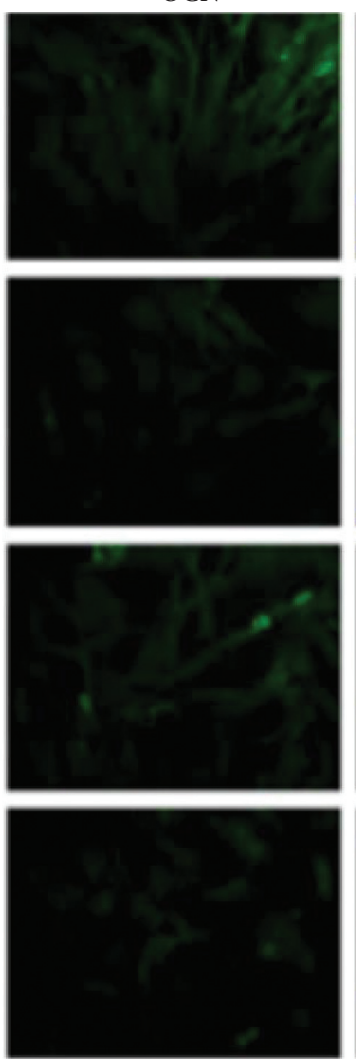

(c)
DAPI
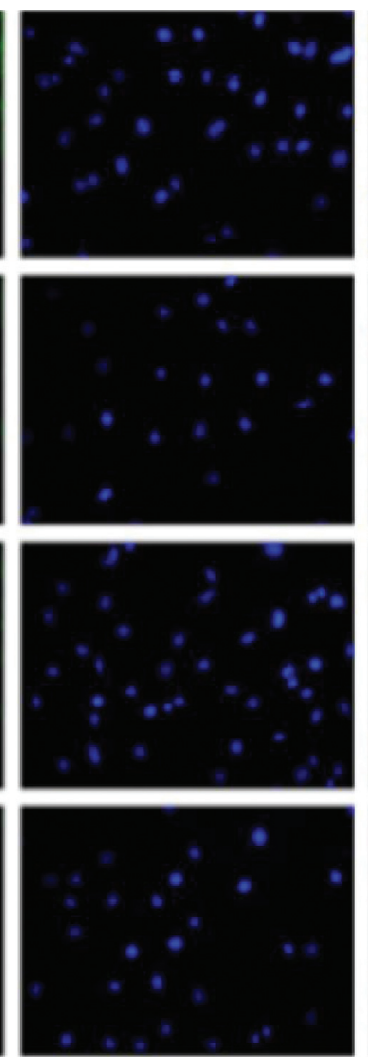

Merge
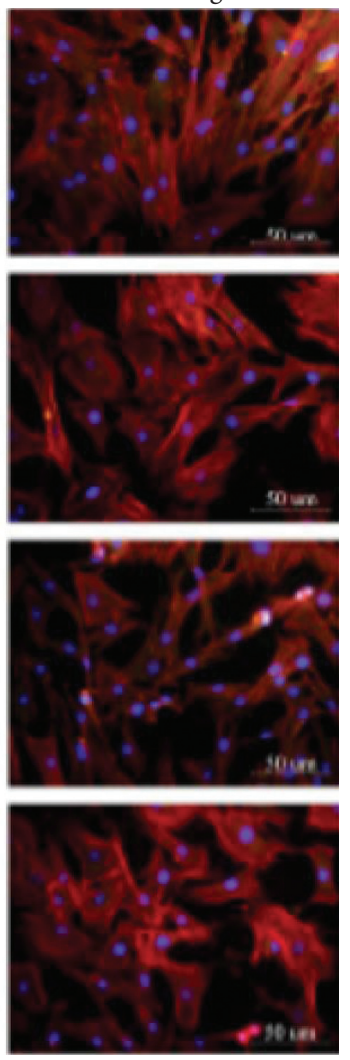

Figure 4: Continued. 

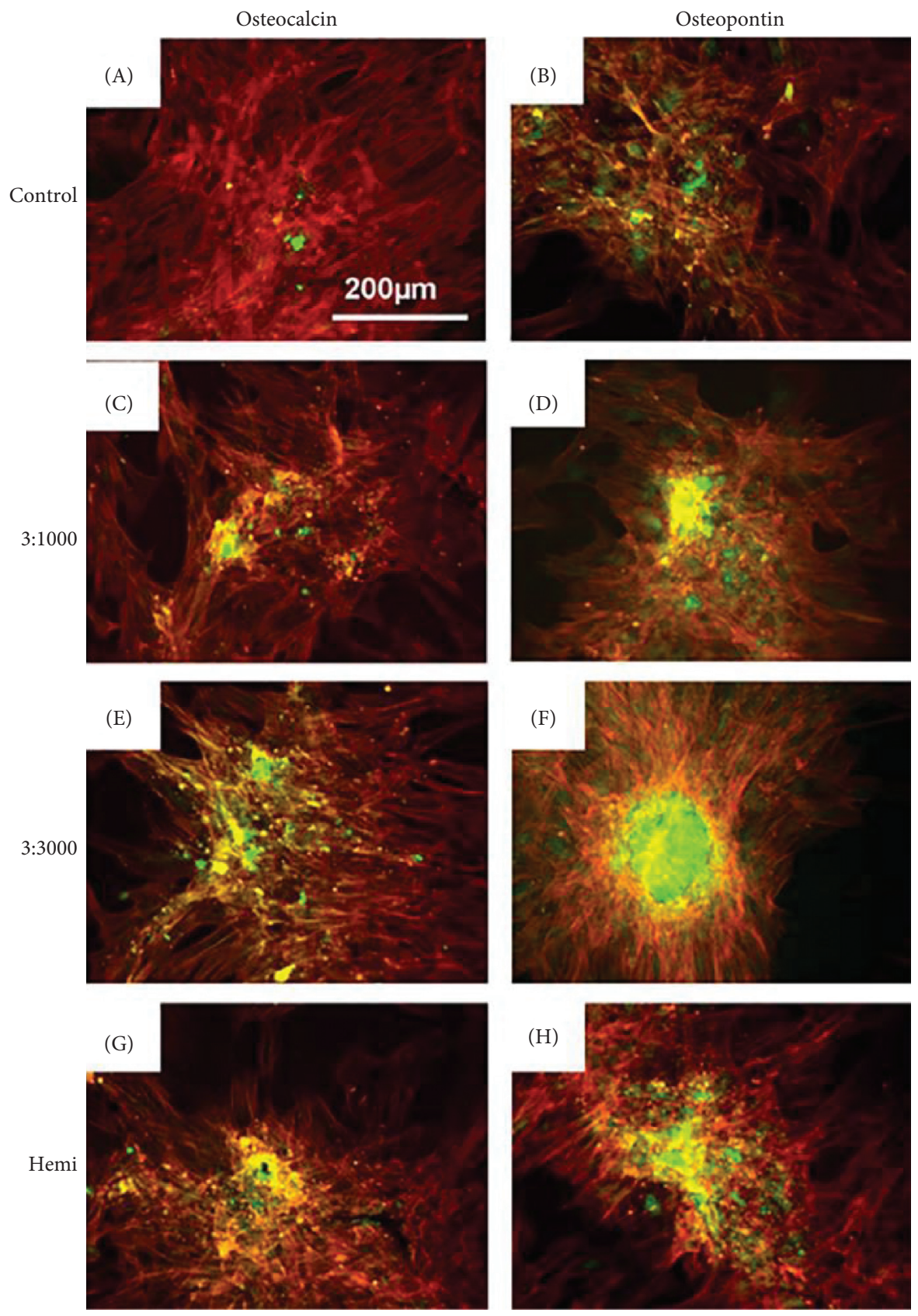

(d)

FIGURE 4: (a) Histochemical staining of calcium phosphate with Alizarin Red S at day 21 after osteogenic differentiation. (b) Immunofluorescence staining of type I collagen (Col (I)) in hADSCs at day 21 after osteogenic differentiation in the presence of BM (basal medium; upper panel) and OM (osteogenic differentiation medium; lower panel) [137] (Copyright 2016, Elsevier). (c) Immunofluorescence and western blotting analysis of osteogenic marker protein in BMSCs cocultured with different scaffolds [139] (Copyright 2017, Royal Society of Chemistry). (d) Osteocalcin (OC) and osteopontin (OPN) fluorescent images for hMSCs cultured on the control and test materials [144] (Copyright 2006, Elsevier).

Moreover, a much higher number of cells were detected on high-stiffness substrates than on low-stiffness gels [146]. Saha et al. revealed that substrate modulus could guide neurogenesis in neural stem cells, in which soft matrices promoted the extension of dendritic processes [147]. Moreover, a pioneering study by Engler and coworkers demonstrated the importance of matrix stiffness in guiding cell differentiation. The authors studied the adhesion of MSCs to collagen-coated polyacrylamide hydrogels of various stiffness [148]. The commitment of MSCs to a specific lineage was based on similarity with the native matrix of committed cells. MSCs cultured on soft polyacrylamide gels $(<1 \mathrm{kPa})$ mimicking the elasticity of the brain developed neuronal-like characteristics. MSCs cultured on 
intermediate stiffness gels $(\sim 10 \mathrm{kPa})$ mimicking the characteristics of muscle committed to myoblast phenotype, whereas those cultured on stiff gels $(>30 \mathrm{kPa})$ mimicking permineralized bone developed osteogenic properties [148].

\section{The Role of the Inflammatory Response in Biomaterial-Induced Bone Regeneration}

Recently, the crosstalk between inflammatory response and osteogenesis has attracted the attention of researchers. In the past, most studies focused on designing biomaterials that directly regulate the differentiation of MSCs. However, recent studies aimed to use bioactive materials to promote osteogenesis via immunomodulation [50, 149-151]. Several recent observations demonstrated that the implant-mediated cytokine production triggers the recruitment and differentiation of stem cells (Figure 5(a)) [152]. For example, a positive linear relationship between the accumulation of inflammatory cells and recruitment of stem cells was found for biomaterials with varying proinflammatory properties [153]. Therefore, for the tissue engineering community, it is important to understand the effects of biomaterials on macrophages to control osteogenic differentiation.

Surface properties of biomaterials, such as chemical composition, surface physical properties, and bioactive molecules, have demonstrated the decisive roles in the interactions between implants-mediated inflammatory response and stem cells [16]. Inflammatory reactions of biomaterials affect the affinity of the stem cells toward an implant and the function of osteoblastic cells. Biomineralization has been widely performed for the fabrication of artificial bone substitutes. Mineralized surfaces can promote the osteogenic differentiation of stem cells. Thus, osteoimmunology of minerals has also been considered a hot and promising field in bone tissue engineering. Wang et al. observed the crosstalk between immune and stem cells cultured on magnesium-calcium phosphate cement by sintering. Although the macrophages seeded on the cement increased the secretion of TGF- $\beta 1$, the secretion of IL- 6 and TNF- $\alpha$ decreased [50]. These changes are beneficial for osteogenic differentiation. Chen et al. found that $\beta$-tricalcium phosphate $(\beta$-TCP), used to coat magnesium scaffolds, promoted macrophages to secrete IL-1RA and BMP-2, thereby inducing a bone healing process and enhancing osseointegration capability (Figure 5(b)) [150]. Other bioactive materials were also reported to affect the crosstalk of macrophages and stem cells. Zhu et al. demonstrated that bioactive glass $(\mathrm{BG}) /$ sodium alginate hydrogel induced the polarization of macrophages in vitro and in vivo toward the M2 phenotype, upregulated the expression of anti-inflammatory genes, and enhanced the synthesis of ECM and differentiation of stem cells [154]. Qiu et al. fabricated an injectable periosteal ECM hydrogel, which not only induced the recruitment and M2-polarization of macrophages but also promoted the differentiation of MSCs into osteoblasts [155].

Wan and coworkers demonstrated that the matrix stiffness and inflammatory factor (interleukin-1 (IL-1b)) played opposite roles in the regulation of osteogenic differentiation, with the inflammatory cytokine IL-1 inhibiting matrix stiffness-induced osteogenic differentiation (Figure 5(c)) [156]. Similarly, $\mathrm{He}$ et al. found that macrophages encapsulated in low-stiffness transglutaminase cross-linked gelatins (TG-gels) exerted a positive effect on the osteogenesis of cocultured BMSCs. In contrast, macrophages encapsulated in high-stiffness TG-gels negatively affected cell osteogenic differentiation when either CMbased incubation or Trans-well-based coculture was used [157].

Bioactive molecules can be loaded on the implant surface by physical or chemical modification. Studies on osteoimmunomodulation by delivering biological molecules have gained comprehensive attention. For instance, Loi et al. investigated the crosstalk between preosteoblasts and macrophages in a direct coculture. IL-4 was used to induce macrophages into the M2 phenotype and subsequently observed increased OSM secretion and osteogenic differentiation [158]. Moreover, Guihard et al. found that OSM, an IL-6 family cytokine produced by activated circulatingCD $14^{+}$or bone marrow $\mathrm{CD} 11 \mathrm{~b}^{+}$monocytes/macrophages, can promote osteoblast differentiation and matrix mineralization of MSCs while inhibiting adipogenesis via signal transducer and activator of transcription (STAT) signaling [48]. It is noteworthy that Spiller et al. used a bone substitute with a short release of IFN- $\gamma$ (M1) and sustained release of IL-4 (M2). To achieve this sequential release profile, IFNg was physically adsorbed onto the scaffolds, whereas IL-4 was attached via biotin-streptavidin binding. The authors showed that the combined M1 and M2 phenotype induction could better promote osteogenic properties [159]. Delivery of growth factor also regulated both immunomodulation and bone formation. Wei et al. prepared a gelatin sponge loaded with BMP-2 and implanted it in mouse subcutaneous tissue for immunoregulation. The results proved that BMP-2 delivery acted as a direct inducible factor for osteogenesis and an indirect regulator of osteogenesis via immune suppression (Figure 5(d)) [160]. Furthermore, the nucleic acid is one of the important factors affecting osteoimmunomodulation. In the study by Li et al., long noncoding ribonucleic acid (lncRNA) MALAT1, an important endogenous regulator of the proliferative, angiogenic, and immunosuppressive properties of MSCs, was used to culture stem cells. Subsequently, the level of indoleamine2,3-dioxygenase in MSC increased and induced M2 dominant macrophage polarization and finally promoted osteogenic differentiation of stem cells [161].

In recent years, remarkable progress has been made in various interdisciplinary fields related to biomaterials research, such as material chemistry, nanotechnology, and material fabrication techniques. However, the biomaterialimmune system interactions and the effects of inflammatory changes (owing to the biomaterials) on the change in tissue healing process remain largely unknown. Thus, research and development of novel biomaterials should be focused on exploring various surface modification strategies for finetuning the control of immune systems. This will allow either avoiding unnecessary inflammation or reprogramming the inflammatory cells to promote the wound healing process 


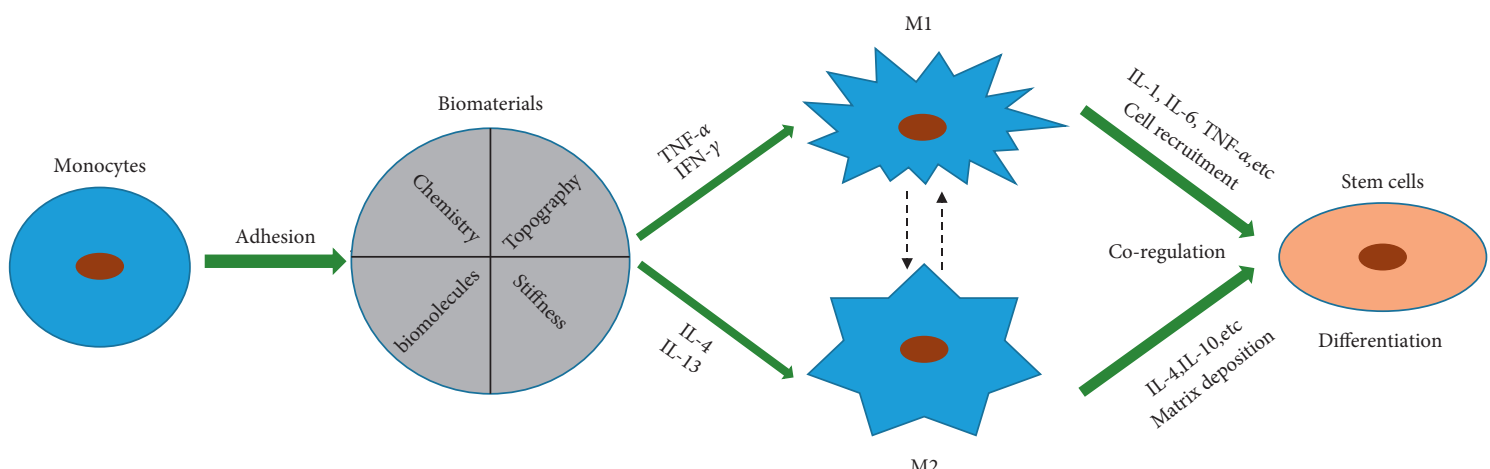

(a)
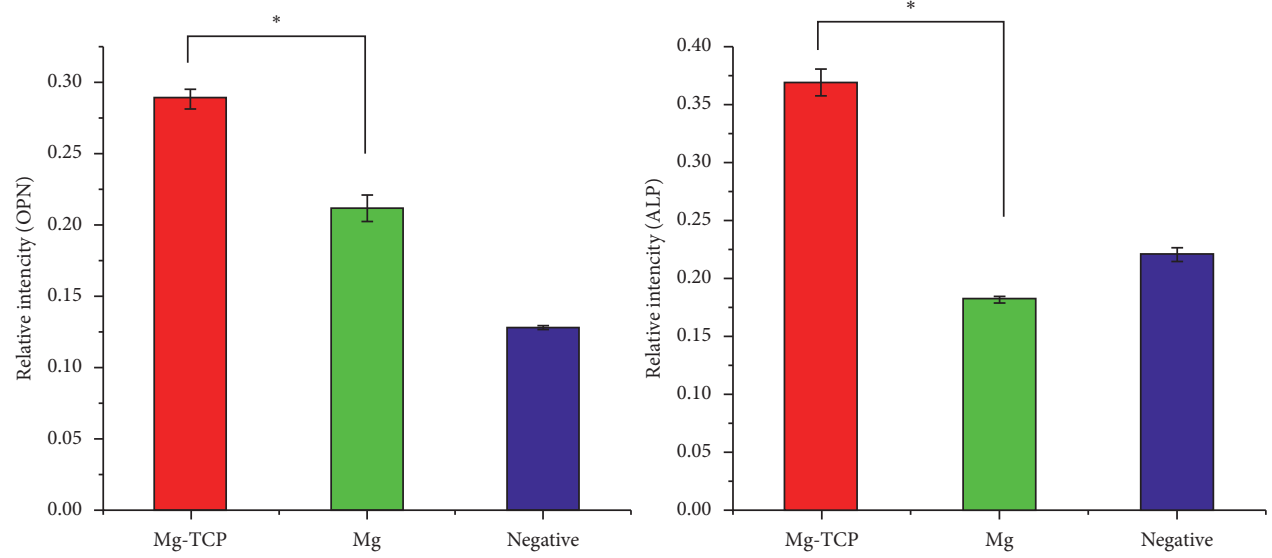

(b)
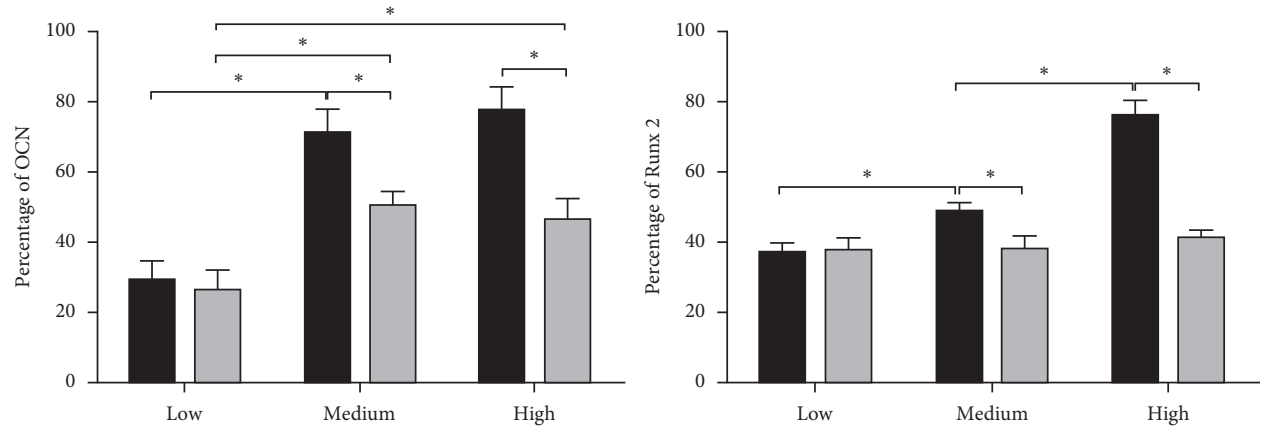

(IL-1 $\beta$ -

口 IL-1 $\beta$ -

$\square \mathrm{IL}-1 \beta+$

$\square \mathrm{IL}-1 \beta+$
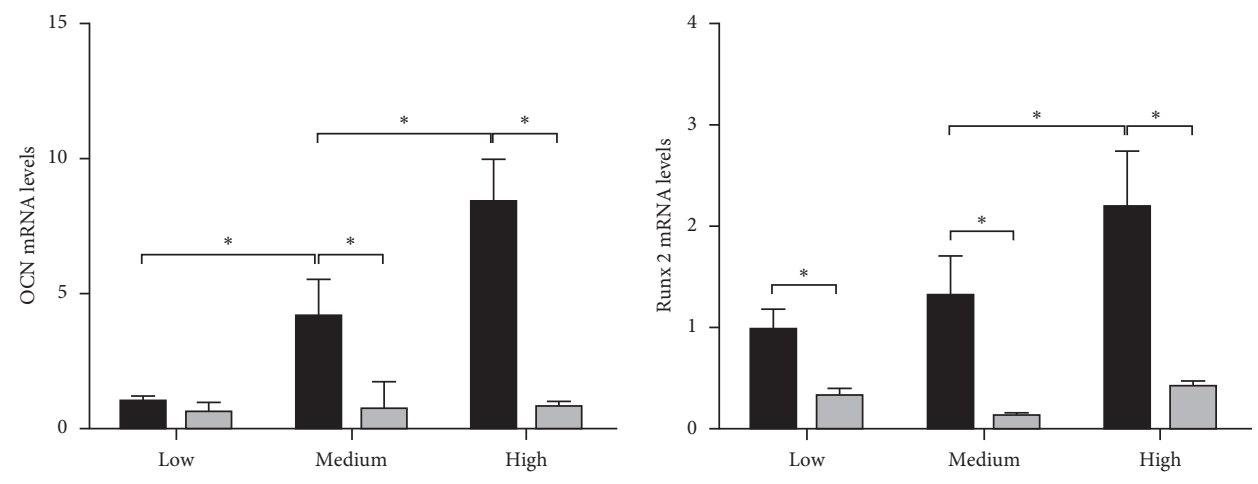

a IL-1 $1 \beta-$

( IL-1 $\beta$ -

$\square \mathrm{IL}-1 \beta+$

$\square \mathrm{IL}-1 \beta+$

(c)

Figure 5: Continued. 

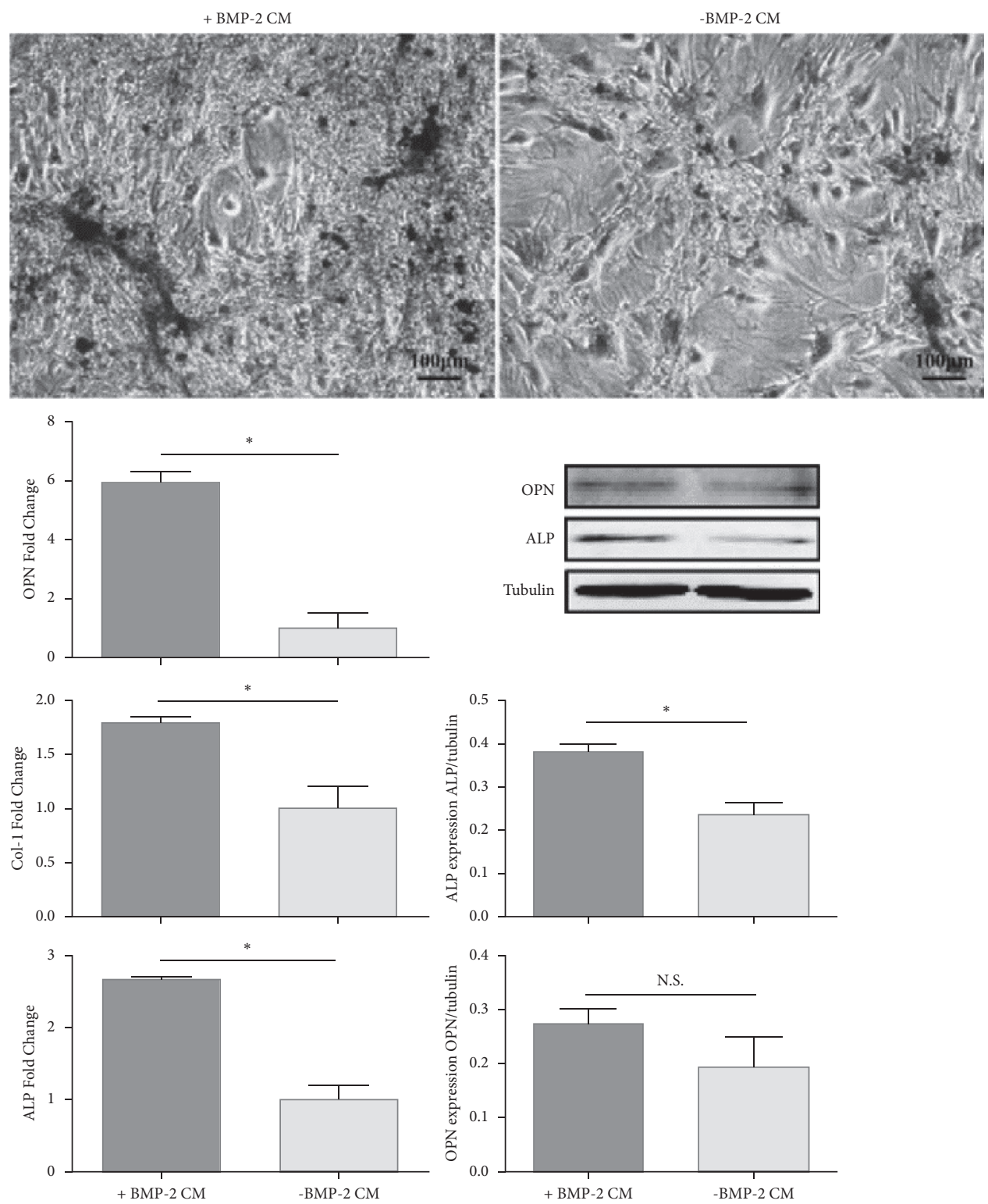

(d)

FIGURE 5: (a) Biomaterials regulate the inflammatory response of macrophages and its role in osteogenesis. (b) The western blotting analysis of OPN and ALP expression by BMSCs cultured in the culture medium (negative) and macrophage/scaffold conditioned medium [150] (Copyright 2104, Elsevier). (c) The quantification of the staining of OCN and Runx2 using ImageJ software and the expression of OCN analyzed by real-time PCR [156] (Copyright 2019, Biophysical Society). (d) Alizarin Red S staining of BMSCs treated with macrophagederived conditioned medium (CM) (+BMP2 CM or -BMP2 CM) in the osteogenic differentiation condition for 21 days; gene expressions of ALP, OPN, and Col I detected by real-time PCR and representative western blots of ALP and OPN after BMSCs were cultured with macrophage-derived CM for 3 days [160] (Copyright 2018, Mary Ann Liebert Inc.).

[16]. Thus, understanding biomaterial-immune cell interactions will significantly contribute to bone regeneration and will open promising venues for the development of bone tissue engineering.

\section{Conclusion and Perspectives}

The application of biomaterials in bone healing greatly relies on the understanding of the fine balance between the inflammatory response of immune cells and repair activity mounted by stem cells. The success of biomaterials for bone regeneration depends not only on how well the biomaterials integrate with in vivo local bone microenvironments but also on the regulation of the key bone healing events. Although surface functionalization of biomaterials can induce enhanced adhesion, proliferation, and differentiation of stem cells, which has been extensively investigated, the role of inflammation as a mediator has not yet been completely understood. Inflammatory reactions accompany the entire osteogenesis process and play pivotal regulatory roles. Thus, 
the response of the macrophages to biomaterials and its role in driving the osteogenic differentiation of MSCs is worth further investigation. Recent studies have revealed that the surface and mechanical properties of biomaterials can be efficiently used to adjust the functions and interplay of the stem and immune cells. Consequently, macrophages have been considered a key cell type in the inflammatory response, and the transformation of macrophage polarization in time and space is a key event that affects osteogenesis. Paracrine action can be the primary mode that affects the osteogenesis of stem cells. Additionally, the influence of biomaterials on the regulation of inflammatory response and its role in osteogenic differentiation of progenitor and stem cells is mainly restricted to in vitro studies and must be further assessed in vivo. Moreover, the study of inflammation should be extended to other critical cells of the immune system, including dendritic and T cells.

\section{Conflicts of Interest}

The authors declare no conflicts of interest with respect to the authorship and/or publication of this review.

\section{Acknowledgments}

This work was partly supported by the National Natural Science Foundation of China (32071326), the Natural Science Foundation of Guangdong Province, China (2019A1515011613 and 2021A1515011196), the Zhanjiang Competitive Funding Project, China (2018A01032 and 2020A01018), the Characteristic Innovation Projects of Guangdong Province Universities (2018KTSCX076), the Stem Cell Preclinical Research Project of Affiliated Hospital of Guangdong Medical University, China (2018PSSC002), and the Summit Project of High-Level Hospital Construction of Affiliated Hospital of Guangdong Medical University (2019083044). TG acknowledges the kind support provided by the Ministry of Science and Higher Education of the Russian Federation within the framework of State Support for the Creation and Development of World-Class Research Centers "Digital Biodesign and Personalized Healthcare" (075-15-2020-926).

\section{References}

[1] S. Font Tellado, E. R. Balmayor, and M. Van Griensven, "Strategies to engineer tendon/ligament-to-bone interface: biomaterials, cells and growth factors," Advanced Drug Delivery Reviews, vol. 94, pp. 126-140, 2015.

[2] O. P. Gautschi, S. P. Frey, and R. Zellweger, "Bone morphogenetic proteins in clinical applications," ANZ Journal of Surgery, vol. 77, no. 8, pp. 626-631, 2007.

[3] E. Gómez-Barrena, P. Rosset, D. Lozano, J. Stanovici, C. Ermthaller, and F. Gerbhard, "Bone fracture healing: cell therapy in delayed unions and nonunions," Bone, vol. 70, pp. 93-101, 2015.

[4] P. V. Giannoudis, H. Dinopoulos, and E. Tsiridis, "Bone substitutes: an update," Injury, vol. 36, no. 3, pp. S20-S27, 2005.

[5] W. G. De Long, T. A. Einhorn, K. Koval et al., "Bone grafts and bone graft substitutes in orthopaedic trauma surgery,"
Journal of Bone and Joint Surgery American Volume, vol. 89, no. 3, pp. 649-658, 2007.

[6] J. C. Banwart, M. A. Asher, and R. S. Hassanein, "Iliac crest bone graft harvest donor site morbidity,” Spine, vol. 20, no. 9, pp. 1055-1060, 1995.

[7] Z. S. Ai-Aql, A. S. Alagl, D. T. Graves, L. C. Gerstenfeld, and T. A. Einhorn, "Molecular mechanisms controlling bone formation during fracture healing and distraction osteogenesis," Journal of Dental Research, vol. 87, no. 2, pp. 107-118, 2008.

[8] X. Chen, Z. Wang, N. Duan, G. Zhu, E. M. Schwarz, and C. Xie, "Osteoblast-osteoclast interactions," Connective Tissue Research, vol. 59, no. 2, pp. 99-107, 2018.

[9] Q. Chen, P. Shou, C. Zheng et al., "Fate decision of mesenchymal stem cells: adipocytes or osteoblasts?" Cell Death \& Differentiation, vol. 23, no. 7, pp. 1128-1139, 2016.

[10] T. Miyamoto, "Role of osteoclasts in regulating hematopoietic stem and progenitor cells," World Journal of Orthopedics, vol. 4, no. 4, pp. 198-206, 2013.

[11] F. Loi, L. A. Córdova, J. Pajarinen, T.-h. Lin, Z. Yao, and S. B. Goodman, "Inflammation, fracture and bone repair," Bone, vol. 86, pp. 119-130, 2016.

[12] S. Franz, S. Rammelt, D. Scharnweber, and J. C. Simon, "Immune responses to implants - a review of the implications for the design of immunomodulatory biomaterials," Biomaterials, vol. 32, no. 28, pp. 6692-6709, 2011.

[13] I. Elgali, O. Omar, C. Dahlin, and P. Thomsen, "Guided bone regeneration: materials and biological mechanisms revisited," European Journal of Oral Sciences, vol. 125, no. 5, pp. 315-337, 2017.

[14] J. Reifenrath, N. Angrisani, N. Erdmann et al., "Degrading magnesium screws ZEK100: biomechanical testing, degradation analysis and soft-tissue biocompatibility in a rabbit model," Biomedical Materials, vol. 8, no. 4, Article ID 045012, 2013.

[15] J. Wang, D. Liu, B. Guo et al., "Role of biphasic calcium phosphate ceramic-mediated secretion of signaling molecules by macrophages in migration and osteoblastic differentiation of MSCs," Acta Biomaterialia, vol. 51, pp. 447-460, 2017.

[16] A. Nair and L. Tang, "Influence of scaffold design on host immune and stem cell responses," Seminars in Immunology, vol. 29, pp. 62-71, 2017.

[17] W. C. Bae, P. C. Chen, C. B. Chung, K. Masuda, D. D’Lima, and J. Du, "Quantitative ultrashort echo time (UTE) MRI of human cortical bone: correlation with porosity and biomechanical properties," Journal of Bone and Mineral Research, vol. 27, no. 4, pp. 848-857, 2012.

[18] D. W. Buck and G. A. Dumanian, "Bone biology and physiology," Plastic and Reconstructive Surgery, vol. 129, no. 6, pp. 1314-1320, 2012.

[19] P. Lips, "Vitamin D deficiency and secondary hyperparathyroidism in the elderly: consequences for bone loss and fractures and therapeutic implications," Endocrine Reviews, vol. 22, no. 4, pp. 477-501, 2001.

[20] B. Clarke, "Normal bone anatomy and physiology," Clinical Journal of the American Society of Nephrology, vol. 3, no. 3, pp. S131-S139, 2008.

[21] R. Fujisawa and Y. Kuboki, "Bone matrix proteins," Nihon Rinsho Japanese Journal of Clinical Medicine, vol. 56, no. 6, pp. 1425-1429, 1998.

[22] A. H. Reddi and R. Marshall, "Marshall R. Urist," Journal of Bone and Joint Surgery American Volume, vol. 85, no. 3, pp. 3-7, 2003. 
[23] S. S. Baloul, "Osteoclastogenesis and osteogenesis during tooth movement," Tooth Movement, vol. 18, pp. 75-79, 2016.

[24] F. Fu and K. Zhang, "Research progress of the role of periosteum in distraction osteogenesis," Chinese Journal of Reparative and Reconstructive Surgery, vol. 31, no. 7, pp. 876-879, 2017.

[25] T. Wang, X. Zhang, and D. D. Bikle, "Osteogenic differentiation of periosteal cells during fracture healing," Journal of Cellular Physiology, vol. 232, no. 5, pp. 913-921, 2017.

[26] L. Han, B. Wang, R. Wang, S. Gong, G. Chen, and W. Xu, "The shift in the balance between osteoblastogenesis and adipogenesis of mesenchymal stem cells mediated by glucocorticoid receptor," Stem Cell Research \& Therapy, vol. 10, no. 1, p. 377, 2019.

[27] M. Fujiwara and K. Ozono, "Cytokines and osteogenesis," Clinical Calcium, vol. 24, no. 6, pp. 845-851, 2014.

[28] S. Mohan and D. J. Baylink, "Bone growth factors," Clinical Orthopaedics and Related Research, vol. 263, pp. 30-48, 1991.

[29] J. Z. Kechagia, J. Ivaska, and P. Roca-Cusachs, "Integrins as biomechanical sensors of the microenvironment," Nature Reviews Molecular Cell Biology, vol. 20, no. 8, pp. 457-473, 2019.

[30] A. Sainio and H. Järveläinen, "Extracellular matrix-cell interactions: focus on therapeutic applications," Cellular Signalling, vol. 66, Article ID 109487, 2020.

[31] M. Schnabelrauch, D. Scharnweber, and J. Schiller, "Sulfated glycosaminoglycans as promising artificial extracellular matrix components to improve the regeneration of tissues," Current Medicinal Chemistry, vol. 20, no. 20, pp. 2501-2523, 2013.

[32] R. O. Hynes, "The extracellular matrix: not just pretty fibrils," Science, vol. 326, no. 5957, pp. 1216-1219, 2009.

[33] D. E. Discher, D. J. Mooney, and P. W. Zandstra, "Growth factors, matrices, and forces combine and control stem cells," Science, vol. 324, no. 5935, pp. 1673-1677, 2009.

[34] B. Geiger, J. P. Spatz, and A. D. Bershadsky, "Environmental sensing through focal adhesions," Nature Reviews Molecular Cell Biology, vol. 10, no. 1, pp. 21-33, 2009.

[35] M. E. Ogle, C. E. Segar, S. Sridhar, and E. A. Botchwey, "Monocytes and macrophages in tissue repair: implications for immunoregenerative biomaterial design," Experimental Biology and Medicine, vol. 241, no. 10, pp. 1084-1097, 2016.

[36] T. A. Einhorn and L. C. Gerstenfeld, "Fracture healing: mechanisms and interventions," Nature Reviews Rheumatology, vol. 11, no. 1, pp. 45-54, 2015.

[37] S. M. Abdelmagid, M. F. Barbe, and F. F. Safadi, "Role of inflammation in the aging bones," Life Sciences, vol. 123, pp. 25-34, 2015.

[38] A. D. Luster, R. Alon, and U. H. von Andrian, "Immune cell migration in inflammation: present and future therapeutic targets," Nature Immunology, vol. 6, no. 12, pp. 1182-1190, 2005.

[39] K. Hamidzadeh, S. M. Christensen, E. Dalby, P. Chandrasekaran, and D. M. Mosser, "Macrophages and the recovery from acute and chronic inflammation," Annual Review of Physiology, vol. 79, no. 1, pp. 567-592, 2017.

[40] A. Mantovani, A. Sica, S. Sozzani, P. Allavena, A. Vecchi, and M. Locati, "The chemokine system in diverse forms of macrophage activation and polarization," Trends in Immunology, vol. 25, no. 12, pp. 677-686, 2004.

[41] M. S. Rahman, N. Akhtar, H. M. Jamil, R. S. Banik, and S. M. Asaduzzaman, "TGF- $\beta /$ BMP signaling and other molecular events: regulation of osteoblastogenesis and bone formation," Bone Research, vol. 3, no. 1, Article ID 15005, 2015.

[42] C. Schlundt, T. El Khassawna, A. Serra et al., "Macrophages in bone fracture healing: their essential role in endochondral ossification," Bone, vol. 106, pp. 78-89, 2018.

[43] L. Claes, S. Recknagel, and A. Ignatius, "Fracture healing under healthy and inflammatory conditions," Nature Reviews Rheumatology, vol. 8, no. 3, pp. 133-143, 2012.

[44] J. Lienau, K. Schmidt-Bleek, A. Peters et al., "Differential regulation of blood vessel formation between standard and delayed bone healing," Journal of Orthopaedic Research, vol. 27, no. 9, pp. 1133-1140, 2009.

[45] T. J. Koh and L. A. DiPietro, "Inflammation and wound healing: the role of the macrophage," Expert Reviews in Molecular Medicine, vol. 13, p. e23, 2011.

[46] M. K. Chang, L.-J. Raggatt, K. A. Alexander et al., "Osteal tissue macrophages are intercalated throughout human and mouse bone lining tissues and regulate osteoblast function in vitro and in vivo," The Journal of Immunology, vol. 181, no. 2, pp. 1232-1244, 2008.

[47] V. Nicolaidou, M. M. Wong, A. N. Redpath et al., "Monocytes induce STAT3 activation in human mesenchymal stem cells to promote osteoblast formation," PloS One, vol. 7, no. 7, Article ID e39871, 2012.

[48] P. Guihard, Y. Danger, B. Brounais et al., "Induction of osteogenesis in mesenchymal stem cells by activated monocytes/macrophages depends on oncostatin $\mathrm{M}$ signaling," Stem Cells, vol. 30, no. 4, pp. 762-772, 2012.

[49] A. Shioi, M. Katagi, Y. Okuno et al., "Induction of bone-type Alkaline phosphatase in human vascular smooth muscle cells," Circulation Research, vol. 91, no. 1, pp. 9-16, 2002.

[50] M. Wang, Y. Yu, K. Dai et al., "Improved osteogenesis and angiogenesis of magnesium-doped calcium phosphate cement via macrophage immunomodulation," Biomaterials Science, vol. 4, no. 11, pp. 1574-1583, 2016.

[51] S. A. Lloyd, Y. Y. Yuan, S. J. Simske, S. E. Riffle, V. L. Ferguson, and T. A. Bateman, "Administration of highdose macrophage colony-stimulating factor increases bone turnover and trabecular volume fraction," Journal of Bone and Mineral Metabolism, vol. 27, no. 5, pp. 546-554, 2009.

[52] D. J. Gow, K. A. Sauter, C. Pridans et al., "Characterisation of a novel Fc conjugate of macrophage colony-stimulating factor," Molecular Therapy, vol. 22, no. 9, pp. 1580-1592, 2014.

[53] V. Garceau, A. Balic, C. Garcia-Morales et al., "The development and maintenance of the mononuclear phagocyte system of the chick is controlled by signals from the macrophage colony-stimulating factor receptor," BMC Biology, vol. 13, no. 1, p. 12, 2015.

[54] K. Zhu, C. Yang, H. Dai et al., "Crocin inhibits titanium particle-induced inflammation and promotes osteogenesis by regulating macrophage polarization," International Immunopharmacology, vol. 76, Article ID 105865, 2019.

[55] T. A. Petrie, N. S. Strand, C. Tsung-Yang, J. S. Rabinowitz, and R. T. Moon, "Macrophages modulate adult zebrafish tail fin regeneration," Development, vol. 141, no. 13, pp. 2581-2591, 2014.

[56] X. Huang, Z. Wang, D. Li et al., "Study of microRNAs targeted Dvl2 on the osteoblasts differentiation of rat BMSCs in hyperlipidemia environment," Journal of Cellular Physiology, vol. 233, no. 9, pp. 6758-6766, 2018.

[57] M. A. Cleary, R. Narcisi, A. Albiero et al., "Dynamic regulation of TWIST1 expression during chondrogenic differentiation of human bone marrow-derived mesenchymal 
stem cells," Stem Cells and Development, vol. 26, no. 10, pp. 751-761, 2017.

[58] T. Yu, M. Gao, P. Yang et al., "Topical insulin accelerates cutaneous wound healing in insulin-resistant diabetic rats," American Journal of Tourism Research, vol. 9, no. 10, pp. 4682-4693, 2017.

[59] E. Karaoz, A. Aksoy, S. Ayhan, A. E. Sarıboyacı, F. Kaymaz, and M. Kasap, "Characterization of mesenchymal stem cells from rat bone marrow: ultrastructural properties, differentiation potential and immunophenotypic markers," Histochemistry and Cell Biology, vol. 132, no. 5, pp. 533-546, 2009.

[60] X. Wei, X. Yang, Z.-P Han, F.-F Qu, L. Shao, and Y.-F Shi, "Mesenchymal stem cells: a new trend for cell therapy," Acta Pharmacologica Sinica, vol. 34, no. 6, pp. 747-754, 2013.

[61] Z. Wang, H. Song, H. Deng, J. Chen, L. Zhang, and Y. Li, "Causes and treatment of long bone fracture nonunion after allogeneic bone grafting surgery," Chinese Journal of Reparative and Reconstructive Surgery, vol. 23, no. 5, pp. 534-537, 2009.

[62] F. Li, N. Whyte, and C. Niyibizi, "Differentiating multipotent mesenchymal stromal cells generate factors that exert paracrine activities on exogenous MSCs: implications for paracrine activities in bone regeneration," Biochemical and Biophysical Research Communications, vol. 426, no. 4, pp. 475-479, 2012.

[63] C. A. Toupadakis, A. Wong, D. C. Genetos et al., "Long-term administration of AMD3100, an antagonist of SDF-1/ CXCR4 signaling, alters fracture repair," Journal of Orthopaedic Research, vol. 30, no. 11, pp. 1853-1859, 2012.

[64] P. Kolar, T. Gaber, C. Perka, G. N. Duda, and F. Buttgereit, "Human early fracture hematoma is characterized by inflammation and hypoxia," Clinical Orthopaedics and Related Research, vol. 469, no. 11, pp. 3118-3126, 2011.

[65] D. J. Ceradini and G. C. Gurtner, "Homing to hypoxia: HIF-1 as a mediator of progenitor cell recruitment to injured tissue," Trends in Cardiovascular Medicine, vol. 15, no. 2, pp. 57-63, 2005.

[66] J. Shao, W. Zhang, and T. Yang, "Using mesenchymal stem cells as a therapy for bone regeneration and repairing," Biological Research, vol. 48, no. 1, p. 62, 2015.

[67] L. Du, P. Yang, and S. Ge, "Stromal cell-derived factor-1 significantly induces proliferation, migration, and collagen type I expression in a human periodontal ligament stem cell subpopulation," Journal of Periodontology, vol. 83, no. 3, pp. 379-388, 2012.

[68] H. Liu, M. Li, L. Du, P. Yang, and S. Ge, "Local administration of stromal cell-derived factor-1 promotes stem cell recruitment and bone regeneration in a rat periodontal bone defect model," Materials Science and Engineering: C, vol. 53, pp. 83-94, 2015.

[69] C. Wu, Y. Zhou, W. Fan et al., "Hypoxia-mimicking mesoporous bioactive glass scaffolds with controllable cobalt ion release for bone tissue engineering," Biomaterials, vol. 33, no. 7, pp. 2076-2085, 2012.

[70] I. A. Janson and A. J. Putnam, "Extracellular matrix elasticity and topography: material-based cues that affect cell function via conserved mechanisms," Journal of Biomedical Materials Research Part A, vol. 103, no. 3, pp. 1246-1258, 2015.

[71] A. W. James, "Review of signaling pathways governing MSC osteogenic and adipogenic differentiation," Scientific, vol. 2013, Article ID 684736, 17 pages, 2013.

[72] A. T. Mehlhorn, P. Niemeyer, K. Kaschte et al., "Differential effects of BMP-2 and TGF- $\beta 1$ on chondrogenic differentiation of adipose derived stem cells," Cell Proliferation, vol. 40, no. 6, pp. 809-823, 2007.

[73] Y.-R. Chou, W.-C. Lo, N. K. Dubey et al., "Platelet-derived biomaterials-mediated improvement of bone injury through migratory ability of embryonic fibroblasts: in vitro and in vivo evidence," Aging, vol. 13, no. 3, pp. 3605-3617, 2021.

[74] X. Qin, Q. Jiang, T. Miyazaki, and T. Komori, "Runx2 regulates cranial suture closure by inducing hedgehog, Fgf, Wnt and Pthlh signaling pathway gene expressions in suture mesenchymal cells," Human Molecular Genetics, vol. 28, no. 6, pp. 896-911, 2019.

[75] K. Lai, Y. Xi, X. Du et al., "Activation of Nell-1 in BMSC sheet promotes implant osseointegration through regulating Runx2/Osterix axis," Frontiers in Cell and Developmental Biology, vol. 8, p. 868, 2020.

[76] A. W. James, A. Pan, M. Chiang et al., "A new function of Nell-1 protein in repressing adipogenic differentiation," Biochemical and Biophysical Research Communications, vol. 411, no. 1, pp. 126-131, 2011.

[77] J.-H. Hong and M. B. Yaffe, "TAZ: a $\beta$-Catenin-like molecule that regulates mesenchymal stem cell differentiation," Cell Cycle, vol. 5, no. 2, pp. 176-179, 2006.

[78] J. Hao, Y. Zhang, Y. Wang et al., "Role of extracellular matrix and YAP/TAZ in cell fate determination," Cellular Signalling, vol. 26, no. 2, pp. 186-191, 2014.

[79] S. Dupont, L. Morsut, M. Aragona et al., "Role of YAP/TAZ in mechanotransduction," Nature, vol. 474, no. 7350, pp. 179-183, 2011.

[80] K.-I. Wada, K. Itoga, T. Okano, S. Yonemura, and H. Sasaki, "Hippo pathway regulation by cell morphology and stress fibers," Development, vol. 138, no. 18, pp. 3907-3914, 2011.

[81] J. Pajarinen, T. Lin, E. Gibon et al., "Mesenchymal stem cellmacrophage crosstalk and bone healing," Biomaterials, vol. 196, pp. 80-89, 2019.

[82] T. Ono and H. Takayanagi, "Osteoimmunology in bone fracture healing," Current Osteoporosis Reports, vol. 15, no. 4, pp. 367-375, 2017.

[83] N. J. Horwood, "Macrophage polarization and bone formation: a review," Clinical Reviews in Allergy and Immunology, vol. 51, no. 1, pp. 79-86, 2016.

[84] J. Rho, M. Takami, and Y. Choi, "Osteoimmunology: interactions of the immune and skeletal systems," Molecules and Cells, vol. 17, no. 1, pp. 1-9, 2004.

[85] A.-L. Gamblin, M. A. Brennan, A. Renaud et al., "Bone tissue formation with human mesenchymal stem cells and biphasic calcium phosphate ceramics: the local implication of osteoclasts and macrophages," Biomaterials, vol. 35, no. 36, pp. 9660-9667, 2014.

[86] G. Tour, M. Wendel, and I. Tcacencu, "Bone marrow stromal cells enhance the osteogenic properties of hydroxyapatite scaffolds by modulating the foreign body reaction," Journal of Tissue Engineering and Regenerative Medicine, vol. 8, no. 11, pp. 841-849, 2014.

[87] L. Y. Lu, F. Loi, K. Nathan et al., "Pro-inflammatory M1 macrophages promote osteogenesis by mesenchymal stem cells via the COX-2-prostaglandin E2 pathway," Journal of Orthopaedic Research, vol. 35, no. 11, pp. 2378-2385, 2017.

[88] O. M. Omar, C. Granéli, K. Ekström et al., "The stimulation of an osteogenic response by classical monocyte activation," Biomaterials, vol. 32, no. 32, pp. 8190-8204, 2011.

[89] L. Gong, Y. Zhao, Y. Zhang, and Z. Ruan, "The macrophage polarization regulates MSC osteoblast differentiation in vitro," Annals of Clinical and Laboratory Science, vol. 46, no. 1, pp. 65-71, 2016. 
[90] Y. Zhang, T. Böse, R. E. Unger, J. A. Jansen, C. J. Kirkpatrick, and J. J. J. P. van den Beucken, "Macrophage type modulates osteogenic differentiation of adipose tissue MSCs," Cell and Tissue Research, vol. 369, no. 2, pp. 273-286, 2017.

[91] P. Quint, M. Ruan, L. Pederson et al., "Sphingosine 1phosphate (S1P) receptors 1 and 2 coordinately induce mesenchymal cell migration through S1P activation of complementary kinase pathways*," Journal of Biological Chemistry, vol. 288, no. 8, pp. 5398-5406, 2013.

[92] L. Pederson, M. Ruan, J. J. Westendorf, S. Khosla, and M. J. Oursler, "Regulation of bone formation by osteoclasts involves Wnt/BMP signaling and the chemokine sphingosine-1-phosphate," Proceedings of the National Academy of Sciences, vol. 105, no. 52, Article ID 20764, 2008.

[93] A. Augello, R. Tasso, S. M. Negrini et al., "Bone marrow mesenchymal progenitor cells inhibit lymphocyte proliferation by activation of the programmed death 1 pathway," European Journal of Immunology, vol. 35, no. 5, pp. 14821490, 2005.

[94] Y.-Z Gu, Q. Xue, Y.-J Chen et al., "Different roles of PD-L1 and FasL in immunomodulation mediated by human placenta-derived mesenchymal stem cells," Human Immunology, vol. 74, no. 3, pp. 267-276, 2013.

[95] M. Di Nicola, C. Carlo-Stella, M. Magni et al., "Human bone marrow stromal cells suppress T-lymphocyte proliferation induced by cellular or nonspecific mitogenic stimuli," Blood, vol. 99, no. 10, pp. 3838-3843, 2002.

[96] S. Aggarwal and M. F. Pittenger, "Human mesenchymal stem cells modulate allogeneic immune cell responses," Blood, vol. 105, no. 4, pp. 1815-1822, 2005.

[97] H. Li, S. Shen, H. Fu et al., "Immunomodulatory functions of mesenchymal stem cells in tissue engineering," Stem Cells International, vol. 2019, Article ID 9671206, 2019.

[98] N. Ebrahim, Y. Mandour, A. Farid et al., "Adipose tissuederived mesenchymal stem cell modulates the immune response of allergic rhinitis in a rat model," International Journal of Molecular Sciences, vol. 20, no. 4, p. 873, 2019.

[99] M. J. Pittet, M. Nahrendorf, and F. K. Swirski, "The journey from stem cell to macrophage," Annals of the New York Academy of Sciences, vol. 1319, no. 1, pp. 1-18, 2014.

[100] T. Asami, M. Ishii, H. Fujii et al., "Modulation of murine macrophage TLR7/8-mediated cytokine expression by mesenchymal stem cell-conditioned medium," Mediators of Inflammation, vol. 2013, Article ID 264260, 13 pages, 2013.

[101] S. Zhang, S. J. Chuah, R. C. Lai, J. H. P. Hui, S. K. Lim, and W. S. Toh, "MSC exosomes mediate cartilage repair by enhancing proliferation, attenuating apoptosis and modulating immune reactivity," Biomaterials, vol. 156, pp. 16-27, 2018.

[102] M. H. Abumaree, M. A. Al Jumah, B. Kalionis et al., "Human placental mesenchymal stem cells (pMSCs) play a role as immune suppressive cells by shifting macrophage differentiation from inflammatory M1 to anti-inflammatory M2 macrophages," Stem Cell Reviews and Reports, vol. 9, no. 5, pp. 620-641, 2013.

[103] D.-I. Cho, M. R. Kim, H.-Y Jeong et al., "Mesenchymal stem cells reciprocally regulate the M1/M2 balance in mouse bone marrow-derived macrophages," Experimental \& Molecular Medicine, vol. 46, no. 1, p. e70, 2014.

[104] R. S. Waterman, S. L. Tomchuck, S. L. Henkle, and A. M. Betancourt, "A new mesenchymal stem cell (MSC) paradigm: polarization into a pro-inflammatory MSC1 or an Immunosuppressive MSC2 phenotype," PloS One, vol. 5, no. 4, Article ID e10088, 2010.
[105] L. Zhu, D. Luo, and Y. Liu, "Effect of the nano/microscale structure of biomaterial scaffolds on bone regeneration," International Journal of Oral Science, vol. 12, no. 1, p. 6, 2020.

[106] K. Hosoyama, C. Lazurko, M. Muñoz, C. D. McTiernan, and E. I. Alarcon, "Peptide-based functional biomaterials for soft-tissue repair," Frontiers in Bioengineering and Biotechnology, vol. 7, p. 205, 2019.

[107] M. Montazerian and E. D. Zanotto, "Bioactive and inert dental glass-ceramics," Journal of Biomedical Materials Research Part A, vol. 105, no. 2, pp. 619-639, 2017.

[108] J. Fu, Y. Su, Y.-X. Qin, Y. Zheng, Y. Wang, and D. Zhu, "Evolution of metallic cardiovascular stent materials: a comparative study among stainless steel, magnesium and zinc," Biomaterials, vol. 230, Article ID 119641, 2020.

[109] J. Lee, H. Byun, S. K. Madhurakkat Perikamana, S. Lee, and H. Shin, "Current advances in immunomodulatory biomaterials for bone regeneration," Advanced Healthcare Materials, vol. 8, no. 4, Article ID 1801106, 2019.

[110] F. Taraballi, M. Sushnitha, C. Tsao et al., "Biomimetic tissue engineering: tuning the immune and inflammatory response to implantable biomaterials," Advanced Healthcare Materials, vol. 7, no. 17, Article ID 1800490, 2018.

[111] R. Klopfleisch and F. Jung, "The pathology of the foreign body reaction against biomaterials," Journal of Biomedical Materials Research Part A, vol. 105, no. 3, pp. 927-940, 2017.

[112] A. K. McNally, J. A. Jones, S. R. Macewan, E. Colton, and J. M. Anderson, "Vitronectin is a critical protein adhesion substrate for IL-4-induced foreign body giant cell formation," Journal of Biomedical Materials Research Part A, vol. 86A, no. 2, pp. 535-543, 2008.

[113] C. R. Jenney and J. M. Anderson, "Adsorbed serum proteins responsible for surface dependent human macrophage behavior," Journal of Biomedical Materials Research, vol. 49, no. 4, pp. 435-447, 2000.

[114] P. Roach, D. Farrar, and C. C. Perry, "Interpretation of protein adsorption: surface-induced conformational changes," Journal of the American Chemical Society, vol. 127, no. 22, pp. 8168-8173, 2005.

[115] J. E. Rayahin and R. A. Gemeinhart, "Activation of macrophages in response to biomaterials," Results \& Problems in Cell Differentiation, vol. 62, pp. 317-351, 2017.

[116] S. Hamlet, M. Alfarsi, R. George, and S. Ivanovski, "The effect of hydrophilic titanium surface modification on macrophage inflammatory cytokine gene expression," Clinical Oral Implants Research, vol. 23, no. 5, pp. 584-590, 2012.

[117] E. Saino, M. L. Focarete, C. Gualandi et al., "Effect of electrospun fiber diameter and alignment on macrophage activation and secretion of proinflammatory cytokines and chemokines," Biomacromolecules, vol. 12, no. 5, pp. 1900-1911, 2011.

[118] A. K. Blakney, M. D. Swartzlander, and S. J. Bryant, "Student award winner in the undergraduate category for the society of biomaterials 9th World Biomaterials Congress, Chengdu, China, June 1-5, 2012," Journal of Biomedical Materials Research Part A, vol. 100A, no. 6, pp. 1375-1386, 2012.

[119] J. Leijten and A. Khademhosseini, "From nano to macro: multiscale materials for improved stem cell culturing and analysis," Cell Stem Cell, vol. 18, no. 1, pp. 20-24, 2016.

[120] E. M. Sussman, M. C. Halpin, J. Muster, R. T. Moon, and B. D. Ratner, "Porous implants modulate healing and induce shifts in local macrophage polarization in the foreign body reaction," Annals of Biomedical Engineering, vol. 42, no. 7, pp. 1508-1516, 2014. 
[121] F. Y. McWhorter, T. Wang, P. Nguyen, T. Chung, and W. F. Liu, "Modulation of macrophage phenotype by cell shape," Proceedings of the National Academy of Sciences, vol. 110, no. 43, pp. 17253-17258, 2013.

[122] G. Zhou, H. Loppnow, and T. Groth, "A macrophage/fibroblast co-culture system using a cell migration chamber to study inflammatory effects of biomaterials," Acta Biomaterialia, vol. 26, pp. 54-63, 2015.

[123] G. Zhou, M. S. Niepel, S. Saretia, and T. Groth, "Reducing the inflammatory responses of biomaterials by surface modification with glycosaminoglycan multilayers," Journal of Biomedical Materials Research Part A, vol. 104, no. 2, pp. 493-502, 2016.

[124] J. A. Jones, D. T. Chang, H. Meyerson et al., "Proteomic analysis and quantification of cytokines and chemokines from biomaterial surface-adherent macrophages and foreign body giant cells," Journal of Biomedical Materials Research Part A, vol. 83A, no. 3, pp. 585-596, 2007.

[125] R. Ion, S. Vizireanu, C. E. Stancu, C. Luculescu, A. Cimpean, and G. Dinescu, "Surface plasma functionalization influences macrophage behavior on carbon nanowalls," Materials Science and Engineering: C, vol. 48, pp. 118-125, 2015.

[126] Y. Yang and Y. Xiao, "Biomaterials regulating bone hematoma for osteogenesis," Advanced Healthcare Materials, vol. 9, no. 23, Article ID 2000726, 2020.

[127] H. Rashidi, J. Yang, and K. M. Shakesheff, "Surface engineering of synthetic polymer materials for tissue engineering and regenerative medicine applications," Biomater. Sci.vol. 2, no. 10, pp. 1318-1331, 2014.

[128] M. S. Corobea, M. G. Albu, R. Ion et al., "Modification of titanium surface with collagen and doxycycline as a new approach in dental implants," Journal of Adhesion Science and Technology, vol. 29, no. 23, pp. 2537-2550, 2015.

[129] A. D. R. Silva, E. M. J. A. Pallone, and A. O. Lobo, "Modification of surfaces of alumina-zirconia porous ceramics with Sr2+ after SBF," Journal of the Australian Ceramic Society, vol. 56, no. 2, pp. 517-524, 2020.

[130] Y.-D. Cho, W.-J. Kim, S. Kim, Y. Ku, and H.-M. Ryoo, "Surface topography of titanium affects their osteogenic potential through DNA methylation," International Journal of Molecular Sciences, vol. 22, no. 5, p. 2406, 2021.

[131] P. Kowalczyk, R. Podgórski, M. Wojasiński, G. Gut, W. Bojar, and T. Ciach, "Chitosan-human bone composite granulates for guided bone regeneration," International Journal of Molecular Sciences, vol. 22, no. 5, p. 2324, 2021.

[132] C. Hu, D. Ashok, D. R. Nisbet, and V. Gautam, "Bioinspired surface modification of orthopedic implants for bone tissue engineering," Biomaterials, vol. 219, Article ID 119366, 2019.

[133] C. Frantz, K. M. Stewart, and V. M. Weaver, "The extracellular matrix at a glance," Journal of Cell Science, vol. 123, no. 24, pp. 4195-4200, 2010.

[134] S. Lee, J.-E. Kim, H.-J. Seo, and J.-H. Jang, "Design of fibronectin type III domains fused to an elastin-like polypeptide for the osteogenic differentiation of human mesenchymal stem cells," Acta Biochimica et Biophysica Sinica, vol. 51, no. 8, pp. 856-863, 2019.

[135] S. L. Bellis, "Advantages of RGD peptides for directing cell association with biomaterials," Biomaterials, vol. 32 , no. 18 , pp. 4205-4210, 2011.

[136] J. E. Frith, R. J. Mills, and J. J. Cooper-White, "Lateral spacing of adhesion peptides influences human mesenchymal stem cell behaviour," Journal of Cell Science, vol. 125, no. 2, pp. 317-327, 2012.
[137] M. Zhao, G. Altankov, U. Grabiec et al., "Molecular composition of GAG-collagen I multilayers affects remodeling of terminal layers and osteogenic differentiation of adiposederived stem cells," Acta Biomaterialia, vol. 41, pp. 86-99, 2016.

[138] L. D. Solorio, E. L. Vieregge, C. D. Dhami, P. N. Dang, and E. Alsberg, "Engineered cartilage via self-assembled hMSC sheets with incorporated biodegradable gelatin microspheres releasing transforming growth factor- $\beta 1$," Journal of Controlled Release, vol. 158, no. 2, pp. 224-232, 2012.

[139] B.-J Zhang, L. He, Z.-W Han et al., "Enhanced osteogenesis of multilayered pore-closed microsphere-immobilized hydroxyapatite scaffold via sequential delivery of osteogenic growth peptide and BMP-2," Journal of Materials Chemistry $B$, vol. 5, no. 41, pp. 8238-8253, 2017.

[140] X. Wang, B. Li, and C. Zhang, "Preparation of BMP-2/ chitosan/hydroxyapatite antibacterial bio-composite coatings on titanium surfaces for bone tissue engineering," Biomedical Microdevices, vol. 21, no. 4, p. 89, 2019.

[141] J. Y. Lim and H. J. Donahue, "Cell sensing and response to micro- and nanostructured surfaces produced by chemical and topographic patterning," Tissue Engineering, vol. 13, no. 8, pp. 1879-1891, 2007.

[142] S. Oh, K. S. Brammer, Y. S. J. Li et al., "Stem cell fate dictated solely by altered nanotube dimension," Proceedings of the National Academy of Sciences, vol. 106, no. 7, pp. 2130-2135, 2009.

[143] D. Kim, J. Kim, H. Hyun, K. Kim, and S. Roh, "A nanoscale ridge/groove pattern arrayed surface enhances adipogenic differentiation of human supernumerary tooth-derived dental pulp stem cells in vitro," Archives of Oral Biology, vol. 59, no. 8, pp. 765-774, 2014.

[144] M. J. Dalby, D. McCloy, M. Robertson et al., “Osteoprogenitor response to semi-ordered and random nanotopographies," Biomaterials, vol. 27, no. 15, pp. 2980-2987, 2006.

[145] P. Jiang, Z. Mao, and C. Gao, "Combinational effect of matrix elasticity and alendronate density on differentiation of rat mesenchymal stem cells," Acta Biomaterialia, vol. 19, pp. 76-84, 2015.

[146] A. S. Rowlands, P. A. George, and J. J. Cooper-White, "Directing osteogenic and myogenic differentiation of MSCs: interplay of stiffness and adhesive ligand presentation," American Journal of Physiology - Cell Physiology, vol. 295, no. 4, pp. C1037-C1044, 2008.

[147] K. Saha, A. J. Keung, E. F. Irwin et al., "Substrate modulus directs neural stem cell behavior," Biophysical Journal, vol. 95, no. 9, pp. 4426-4438, 2008.

[148] A. J. Engler, S. Sen, H. L. Sweeney, and D. E. Discher, "Matrix elasticity directs stem cell lineage specification," Cell, vol. 126, no. 4, pp. 677-689, 2006.

[149] J. Vlacic-Zischke, S. M. Hamlet, T. Friis, M. S. Tonetti, and S. Ivanovski, "The influence of surface microroughness and hydrophilicity of titanium on the up-regulation of TGF $\beta$ / BMP signalling in osteoblasts," Biomaterials, vol. 32, no. 3, pp. 665-671, 2011.

[150] Z. Chen, X. Mao, L. Tan et al., "Osteoimmunomodulatory properties of magnesium scaffolds coated with $\beta$-tricalcium phosphate," Biomaterials, vol. 35 , no. 30 , pp. 8553-8565, 2014.

[151] C.-H. Lee, Y.-J. Kim, J.-H. Jang, and J.-W. Park, "Modulating macrophage polarization with divalent cations in nanostructured titanium implant surfaces," Nanotechnology, vol. 27, no. 8, Article ID 085101, 2016. 
[152] D. Yang, J. Xiao, B. Wang, L. Li, X. Kong, and J. Liao, "The immune reaction and degradation fate of scaffold in cartilage/bone tissue engineering," Materials Science and Engineering: $C$, vol. 104, Article ID 109927, 2019.

[153] A. Nair, J. Shen, P. Lotfi, C.-Y. Ko, C. C. Zhang, and L. Tang, "Biomaterial implants mediate autologous stem cell recruitment in mice," Acta Biomaterialia, vol. 7, no. 11, pp. 3887-3895, 2011.

[154] Y. Zhu, Z. Ma, L. Kong, Y. He, H. F. Chan, and H. Li, "Modulation of macrophages by bioactive glass/sodium alginate hydrogel is crucial in skin regeneration enhancement," Biomaterials, vol. 256, Article ID 120216, 2020.

[155] P. Qiu, M. Li, K. Chen et al., "Periosteal matrix-derived hydrogel promotes bone repair through an early immune regulation coupled with enhanced angio- and osteogenesis," Biomaterials, vol. 227, Article ID 119552, 2020.

[156] W. Wan, B. Cheng, C. Zhang et al., "Synergistic effect of matrix stiffness and inflammatory factors on osteogenic differentiation of MSC," Biophysical Journal, vol. 117, no. 1, pp. 129-142, 2019.

[157] X.-T. He, R.-X. Wu, X.-Y. Xu, J. Wang, Y. Yin, and F.-M. Chen, "Macrophage involvement affects matrix stiffness-related influences on cell osteogenesis under three-dimensional culture conditions," Acta Biomaterialia, vol. 71, pp. 132-147, 2018.

[158] F. Loi, L. A. Córdova, R. Zhang et al., "The effects of immunomodulation by macrophage subsets on osteogenesis in vitro," Stem Cell Research \& Therapy, vol. 7, no. 1, p. 15, 2016.

[159] K. L. Spiller, S. Nassiri, C. E. Witherel et al., "Sequential delivery of immunomodulatory cytokines to facilitate the M1-to-M2 transition of macrophages and enhance vascularization of bone scaffolds," Biomaterials, vol. 37, pp. 194207, 2015.

[160] F. Wei, Y. Zhou, J. Wang, C. Liu, and Y. Xiao, "The immunomodulatory role of BMP-2 on macrophages to accelerate osteogenesis," Tissue Engineering Part A, vol. 24, no. 7-8, pp. 584-594, 2018.

[161] X. Li, Y. Song, F. Liu et al., "Long non-coding rna MALAT1 promotes proliferation, angiogenesis, and immunosuppressive properties of mesenchymal stem cells by inducing VEGF and ido," Journal of Cellular Biochemistry, vol. 118, no. 9, pp. 2780-2791, 2017. 